\title{
Past performance may be an illusion: Performance, flows, and fees in mutual funds
}

\author{
Blake Phillips, Kuntara Pukthuanthong, and P. Raghavendra Rau*
}

Critical Finance Review, forthcoming

Mutual funds report performance in the form of a holding period return (HPR) over standardized horizons. Changes in HPRs are equally influenced by new and previously reported stale returns which enter and exit the horizon. Investors appear unable to differentiate between the joint determinants, reacting with equal strength to both signals. Stale performance chasing is amplified for funds which promote performance via advertising and is more pronounced during periods of uncertainty in financial markets. Fund managers exploit this behavior by preferentially timing fee increases to align with periods of heightened investor demand resulting from stale performance chasing.

Keywords: Limited attention; Behavioral finance; Investor psychology; Capital markets; Horizon Effects; Mutual fund fee-setting

\footnotetext{
* Phillips: School of Accounting and Finance, University of Waterloo, 200 University Avenue West, Waterloo, Ontario, N2L 3G1, Canada, (519) 888 4567, brphilli@uwaterloo.ca; Pukthuanthong: Robert Trulaske Sr. College of Business, University of Missouri, Cornell Hall, Columbia, Missouri, USA 65211, (573) 884-9785 and Rau: University of Cambridge, Trumpington Street, Cambridge CB3 9LR, UK, (44) (1223) 761079 , r.rau@jbs.cam.ac.uk. Phillips gratefully acknowledges financial support from the School of Accounting and Finance at the University of Waterloo, PricewaterhouseCoopers and the Social Sciences and Humanities Research Council of Canada. We would like to thank Neil Brisley, Joe Chen, Susan Christoffersen, Mike Cooper, Javier Gil-Bazo, Will Goetzmann, Russell Jame, Petri Jylha, Jonathan Reuter, Laura Starks, William Stroker, Ivo Welch (Editor), Tony Wirjanto, Jeff Wurgler, three anonymous referees and seminar participants at the 2012 Annual Meeting of the Academy of Behavioral Finance and Economics, the 2012 Northern Finance Association Conference, the 2013 SFS Cavalcade conference, the 2013 European Finance Association meetings, the 2013 Financial Management Association meetings, the 2013 Inquire UK conference, and the University of Waterloo for helpful comments.
} 


\section{Past performance may be an illusion: Performance, flows, and fees in mutual funds}

Mutual funds report performance in the form of a holding period return (HPR) over standardized horizons. Changes in HPRs are equally influenced by new and previously reported stale returns which enter and exit the horizon. Investors appear unable to differentiate between the joint determinants, reacting with equal strength to both signals. Stale performance chasing is amplified for funds which promote performance via advertising and is more pronounced during periods of uncertainty in financial markets. Fund managers exploit this behavior by preferentially timing fee increases to align with periods of heightened investor demand resulting from stale performance chasing.

Keywords: Limited attention; Behavioral finance; Investor psychology; Capital markets; Horizon Effects; Mutual fund fee-setting 
Singer Tom Petty once warbled that the waiting is the hardest part. Now that wait is finally over for many mutual-fund managers. That is because 2007 marks a milestone that could greatly help their funds: It will have been five long years since the late-2002 bear-market bottom. This means that five-year performance numbers no longer will reflect the market's steep slide. Instead, they will capture the market's upswing since then. Funds took the brunt of the dot-com bust at different times. January 2002, for instance, was a particular low for Old Mutual Focused Fund, which had a sinking, large position in Adelphia Communications Corp., a cable company that eventually filed for bankruptcy-court protection. "I'm very anxious to roll off that quarter specifically," says Jerome Heppelmann, manager of the fund. Its five-year annualized return has more than doubled to 6.4\% through December 2006, compared with a 2.8\%-a-year gain at the end of $2005{ }^{1}$

\section{Introduction}

One of the most persistent and robust patterns documented in the mutual fund literature is return-chasing by investors. ${ }^{2}$ The disproportional allocation of wealth to funds with superior performance in prior periods transcends mutual fund asset classes, country boundaries, and investment objectives. Given the limited evidence of persistence in mutual fund performance (Berk and Green, 2004), this trend is largely described in the popular press as irrational. For example, on the heels of the 1999 bull market, concerns regarding the potentially detrimental impacts of return-chasing led then Securities and Exchange Commission (SEC) Chairman Arthur Levitt to caution investors against this practice, stating "Chasing fund performance is often the quickest way to hurt your mutual fund returns". ${ }^{3}$

In this paper, we examine a different type of return-chasing behavior. Without exception, the return-chasing literature has focused on investor reaction to the most recent fund return. We analyze whether investors chase stale fund returns, returns arising from horizon effects in holding period returns (HPR), the standard format of performance reporting. Due to either

\footnotetext{
${ }^{1}$ Diya Gullappalli, The mutual-funds eraser, Wall Street Journal, January 26, 2007.

${ }^{2}$ For example, Barber, Odean and Zheng (2000) report that over half of all fund purchases are of funds ranked in the top quintile of prior annual returns. Also see Ippolito (1992); Chevalier and Ellison (1997); Sirri and Tufano (1998); Lynch and Musto (2003) and Karceski (2002).

3 SEC press release 2000-7, New SEC mutual fund tips remind investors to look at more than short-term past performance.
} 
naïvety or limited attention, investors appear unable to distinguish between the new and stale components of changes in HPRs when making allocations, and misconstrue the changes in returns as new information regarding manager ability and future fund performance. We document how this stale return-chasing effect is used by funds to attract investor allocations and set fees and argue that this type of behavior is part of a general class of horizon effects that have implications for other areas of finance including the asset pricing literature.

Specifically, when advertising past performance, Rule 482 of the Securities Act of 1933 requires investment companies to report past performance in the form of an HPR over horizons of 1,5 , and 10 years for funds in existence over those horizons. The horizon must be at least one year long and must end with the latest calendar quarter. These requirements are designed to standardize performance reporting across funds and ensure that fund managers are not selecting arbitrary horizons to maximize their reported performance. Investment companies are free to report other horizons as long as their prominence is not greater than the required horizons. In particular, as a matter of convention, mutual funds typically also report the 3-year HPR, perhaps because mutual fund rating agencies such as Morningstar or Lipper also rank funds on the basis of their past $1,3,5$, and 10 year HPRs.

The focus of our analysis is how investors interpret the change in reported HPRs. For example, consider the following 5 quarter return time series:

$\begin{array}{cccccc}\text { Period } & -1 & -2 & -3 & -4 & -5 \\ \text { Return } & -2 \% & 3 \% & 4 \% & 5 \% & -4 \%\end{array}$

The annual HPR for quarters -2 to -5 is $8 \%$ and the corresponding annual HPR for quarters -1 to -4 is $10 \%$ :

$$
\begin{aligned}
& H P R_{t-1}=[(1+-0.02)(1+0.03)(1+0.04)(1+0.05)]-1=0.102 \\
& H P R_{t-2}=[(1+0.03)(1+0.04)(1+0.05)(1+-0.04)]-1=0.079
\end{aligned}
$$

Even though the fund experienced a negative return in the most recent period $(t=-1)$, the HPR increased as the end-return which dropped from the sample was more negative. The change in the HPR is therefore a function of the most recent return (-2\%) which enters the horizon and the 
end-return (-4\%) which drops from the horizon. As all other intervening returns are common in the return sequences, they have no influence on the change in the HPR. Thus, the change in HPR is influenced only by new information (reflected in the most recent fund return), and stale information (reflected in the end-return that was reported to investors four quarters previously).

As illustrated by the introductory quote, mutual fund managers appear to view the stale information component impounded in the change in the HPR as an important influence on investor behavior. The manager quoted is "anxious to roll off" a quarter with particularly poor performance. In other words, the manager anticipates an improvement in the fund's reported performance because a negative end-return drops from the horizon of the HPR calculation. However, the improvement in the reported HPR implies only that immediate performance was less negative than the quarter being rolled off. After controlling for the most recent return, the change in the HPR does not provide any new or relevant information regarding future fund performance. To our knowledge, the extent to which stale returns influence investor behavior has yet to be explored.

If investors have access to the entire time series of fund returns, the change in the HPR can easily be decomposed into new and stale information components. It is plausible that at least some investors have access to this information. Our analysis spans the period of 1992 to 2010, during which the availability of mutual fund information expanded dramatically, evolving from paper disclosures by mutual funds to the SEC to electronic availability of mutual fund disclosures and related data via EDGAR and data providers such as Morningstar. However, we argue that they do not necessarily use this information. Hirshleifer and Teoh (2003) argue that investors have limited attention and processing power and potentially lack the sophistication to interpret the disclosed information. In our setting, regardless of the availability of past returns, investors are overwhelmed by the volume of public information available to assess mutual fund quality and thus gravitate to information that is presented in a salient, easily processed form. Further, it is not clear that the average retail investor understands the manner in which HPRs are calculated and consequently the influence of stale information when evaluating the time series of 
HPRs. The computation procedure is not reported and only investors with some level of finance education would understand the nuances of performance reporting.

We document three results in the paper. First, analyzing investor allocations, we find that investors appear unable to differentiate between the new and stale information components of performance reported by mutual funds. It is well understood that investors "chase" past performance, allocating disproportional wealth to funds with strong recent performance. Our results suggest that investors react with equal vigor to the stale information component of HPRs. In other words, investors direct disproportionate flows to funds which realize improved HPRs due to end-returns dropping from the horizon of HPR calculations. Second, mutual fund managers specifically cater to and exploit this behavior by advertising end-return related improvements in reported performance. Third, mutual fund managers also align fee increases with periods of artificially heighted fund demand resulting from end-return related increases in performance, harming existing investors who pay higher fees for the same fund and potentially leaving new investors worse off.

Specifically, examining the universe of actively managed, domestic mutual funds in the U.S., we first show that investors react to the stale information component in HPRs. In separate regressions, we relate measures of mutual fund capital allocations and redemptions in month $t$ to fund return in month $t-1$ (new information) plus, in sequence, each of the other monthly return lags up to lag 73 (stale information). For example, the first regression includes the fund returns in $t-1$ and $t-2$ as independent variables, the second regression includes the fund returns in $t-1$ and $t-3$ as independent variables, and so forth across 72 separate regressions. This approach allows us to decompose investor reaction to the change in HPR into new and end-return components. We then exploit differences in visibility of different return lags. Given that mutual funds are constrained to report HPRs over specific horizons, investor sensitivity to end-return effects should manifest only for lags specific to those horizons (specifically the $13^{\text {th }}, 37^{\text {th }}$, and $61^{\text {st }}$ return lag in our setting, relating to the 1,3 , and 5 year HPR). If investors are influenced by horizon effects, controlling for the new information conveyed by the return from period $t-1$, we expect those specific return lags to be associated with large and negative allocations to mutual funds, as 
the removal of an observation from the HPR calculation has an inverse effect on the magnitude of the HPR.

This is precisely what we find. On average, mutual fund investor allocations are more than twice as sensitive to return observations realized 13, 37, and 61 months prior than in other months and the coefficients on these return lags are all significantly negative. Although flow sensitivity to lagged performance is non-zero for many lags, only the coefficients for the $13^{\text {th }}$, $37^{\text {th }}$, and $61^{\text {st }}$ return lags are also consistently statistically different from the average sensitivity to lagged performance. Further, the magnitude of investor sensitivity to these return lags is of equal or greater magnitude to return-chasing on the first return lag. Investors appear unable to recognize the influence of time on HPR calculation horizons and direct disproportionate flows towards funds which benefit from the statute of limitations expiring on prior poor performance. We refer to this as stale return chasing.

Stale return chasing behavior is consistent with incentives created by advertising. We show that mutual funds preferentially promote high HPRs and time advertising to periods when the 1,3, and 5 year horizon HPRs are coincidentally high. This might not appear to be surprising since funds would be expected to selectively promote high returns. However, controlling for these incentives, we find that advertising spending is incrementally higher when the fund has benefited from end-return related improvements in HPRs. In other words, mutual funds appear to preferentially promote performance measures that arise from poor returns dropping off the end of the reported horizon. This is also not entirely surprising. It is easier to time advertising around predictable improvements in HPRs, resulting from negative end-returns dropping from the HPR horizon. These can be anticipated well in advanced and allow time for campaign development. Of course, future HPRs cannot be perfectly forecasted as they are equally influenced by the new return (which cannot be predicted) and the end-return which can be perfectly anticipated. However, as discussed in the introductory quote, in instances when the end-return is sufficiently large and negative, a relative improvement in HPRs can be easily foreseen. In additional results, we find that the horizon effect is more pronounced for funds with greater marketing expenditures 
and the effect is most pronounced for fund-specific advertising that features HPR information or horizon specific rankings.

In the final part of the paper, relating the total expense ratio of the fund to our stale performance effect measures and controls, we find that mutual funds time fee increases by reducing waivers to coincide with periods of positive performance caused by negative endreturns dropping from the HPR horizon. A one standard deviation increase in the stale performance signal is associated with a $20 \%$ increase in the fund's expense ratio. The cost to newly attracted investors is hard to quantify as we are unable to observe the counterfactual choice - what investors would have purchased if they did not purchase this fund. Fee increases are incrementally higher when investor demand arises from stale performance signals. Unreported tests show that future fund performance is unrelated to stale performance chasing. However, existing investors are clearly harmed, paying higher fees for the same fund. In addition, this behavior distorts competition between mutual funds for investor allocations, rewarding managers who generate administrative costs running uninformative advertising.

Our results contribute to the growing literature on how investors with limited attention react to information. Cooper, Gulen, and Rau (2005) argue that investors are influenced by cosmetic effects. They show that mutual funds attract flows by changing their names to the current hot style with little underlying change in portfolio holdings. Barber, Odean, and Zheng (2005) argue that the purchase decisions of mutual fund investors are influenced by salient, attention-grabbing information. Investors buy funds that attract their attention through exceptional performance, marketing, or advertising. We show that investors also react to apparent increases in performance which occur as a function of horizon effects in the required reporting form.

The most novel contribution of our paper, however, is the examination of opportunistic behavior by managers. There is limited evidence in the literature on the channels through which managers take advantage of behavioral biases. Li (2008) shows that annual report readability is related to earnings persistence as the annual reports of firms with lower earnings are harder to read. He argues that this is consistent with managerial incentives to obfuscate information when 
firm performance is bad (also see Bloomfield, 2002). Mullainathan, Schwartzstein, and Shleifer (2008) develop an uninformative persuasion model where individuals think coarsely, grouping situations in categories and applying the same models of inference to all situations in the same category. They show that persuaders take advantage of coarse thinking by framing objectively useless information to influence individual's choice of category. Bertrand, et al. (2010) argue that advertising content persuades by appealing peripherally to intuition rather than reason. Our research provides new evidence on how and when mutual funds use uninformative information (i.e. stale performance signals) to persuade investors that they are high-performance or quality funds.

Palmiter and Taha (2012) argue that performance advertising by mutual funds is inherently and materially misleading, violates federal securities antifraud standards, and takes advantage of naïve investors. Provisions under the 2010 Dodd-Frank Wall Street Reform and Consumer Protection Act require further intervention by the SEC. ${ }^{4}$ To our knowledge, we are the first to document evidence consistent with funds planning advertising campaigns based on stale performance information and then strategically increasing fees to exploit return-chasing based on stale information. Our results are broadly consistent with mutual fund performance advertising misleading investors who do not appear to appreciate the influence of horizons on reported fund performance.

Finally, our results may offer an economic mechanism to explain the horizon effects found in the asset pricing literature. It is well known in that literature that high stock returns in a month tend to forecast high stock returns 12-, 24-, and 36-months ahead (Jegadeesh, 1990, Heston and Sadka, 2008, 2010, Goyal and Wahal, 2013). While these papers do not explain why these effects appear to be most significant at annual return horizons, they may be related to investor reactions to reported performance at those horizons.

\footnotetext{
${ }^{4}$ Specifically, the Act requires the Government Accountability Office to conduct a study on mutual fund advertising to identify (1) existing and proposed regulatory requirements for open-end investment company advertisements, (2) current marketing practices for the sale of open-end investment company shares, including the use of past performance data, (3) the impact of such advertising on consumers, and (4) recommendations to improve investor protections in mutual fund advertising and additional information necessary to ensure that investors can make informed financial decisions when purchasing shares. See the Dodd-Frank Wall Street Reform and Consumer Protection Act, Pub. L. No. 111-203, § 918, 124 Stat. 1376, 1837 (2010).
} 


\section{Literature Review and the General Setting}

Mutual funds are predominantly held by individual investors. In $2012,44 \%$ of US households held mutual funds and $89 \%$ of US mutual fund assets were held by households. The median income of households which invest in mutual funds was $\$ 80,000$ and $68 \%$ of those households held over $50 \%$ of financial assets in mutual funds..$^{5}$ Thus, the typical mutual fund investor is an individual with limited time, whose professional training is likely focused on a non-financial field, and who potentially lacks the expertise to make investment selections.

Due to the large number of funds available and the wealth of information provided by investment companies, analysts, and other investors via social networks, it is plausible that investors have only limited attention to devote to picking an appropriate mutual fund. Evaluating the merits of an actively managed mutual fund involves assessment of the asset picking and market timing ability of the manager as well as the inherent risk exposures of the fund's assets. Individual investors must allocate attention to work and personal life, in addition to making investment decisions. Directing attention to a specific task requires effort and necessitates exclusion of other tasks (Fiske, 1995) and tends to be directed to information that is more vivid or salient (i.e. which is more prominent or which stands out). ${ }^{6}$ Further, the manner in which attention is allocated depends on the ease with which "relevant instances come to mind" (availability heuristic, Kahneman and Tversky, 1973).

In our setting, HPRs feature extremely prominently in mutual fund advertising and analyst reports and are likely perceived as readily comprehensible by investors, thus being appealing both in terms of salience and availability. A sample mutual fund advertisement appears in panel A of Figure 1, providing a sense of the prominence of the HPR. Interpreting the returns disclosed in the advertisement, an investor may perceive that fund performance has steadily

\footnotetext{
${ }^{5}$ See the 2013 Investment Company Institute Fact Book, $53^{\text {rd }}$ Edition.

${ }^{6}$ For example, Amir (1993) reports that footnote disclosure of post-retirement benefits are underweighted by investors. See also the discussion by Fiske and Taylor (1991).
} 
improved (reflected by the 1 year relative to the 3 year HPR). Beyond contrasting adjacent horizons, investors may also contrast changes in common horizons across timeframes (i.e. comparing the 1 year HPR in the current and previous quarters). However, as previously discussed, given the information in the advertisement, it is impossible for the investor to discern if the higher 1 year performance is due to a low end-return dropping from the 1 year horizon or strong recent performance. To disentangle the new and stale information components impounded in the reported HPRs, investors must access higher frequency return data. This requires a greater allocation of attention, assuming the investor is sophisticated enough to understand the need for such additional effort.

There is evidence that even sophisticated investors, such as analysts, are influenced by the form and prominence of financial disclosures. For example, Hand (1990) reports abnormal reaction to re-announced gains from debt-equity swaps in quarterly earnings announcements and Plumlee (2003) finds that analyst's revisions of forecasts of effective tax rates reflect less complex tax law changes but not more complicated information. Thus, even if investors understand the nuances of HPR reporting, framing or inattention may lead to misinterpretation of reported mutual fund performance.

\section{Measuring Investor Reaction to Stale Performance}

We obtain mutual fund data from the Center for Research in Security Prices (CRSP) Mutual Fund Database. Our sample commences in 1992, when CRSP consistently begins reporting monthly frequency total net asset (TNA) values and concludes in December 2010. The CRSP database provides monthly TNA and returns by fund share class as well as quarterly or annual disclosures of management and 12b-1 fees, front and back end loads, portfolio turnover, and fund management objectives. We aggregate multiple share classes of the same fund, weighting returns, fees, loads and portfolio turnover by share class TNA, and focus our analysis 
on actively managed, domestic equity funds. ${ }^{7}$ The early part of the time series of our dataset (1992-1998) includes on average 1,774 funds, provided by 470 separate investment companies (fund families) with a combined TNA of 1.0 trillion USD. Our dataset expands to include on average 3,093 funds, 534 families, and a combined TNA of 3.7 trillion USD in the later part of the data time series (2005-2010).

To measure the stale performance effect, we relate proxies for investor allocation preferences to the first return lag plus successive return lags ( $n=2$ to 73 ), in 72 separate regressions:

$$
\Delta m_{t}=\alpha+\beta_{1} R_{t-1}+\beta_{t-n} R_{t-n}+\epsilon_{t}
$$

where $n$ signifies the lag of the second return included as an independent variable in month $t$. The primary measure of investor preferences is the change in market share held by the fund, defined as:

$$
\Delta m_{i, t}=\frac{n_{i, t}}{\widehat{N}_{t}}-\frac{n_{i, t-1}}{\widehat{N}_{t-1}}
$$

where $n_{i, t}$ is total net assets under management for fund $i$ in month $t$, and $\widehat{N}_{t}$ is aggregate total net assets for all funds in the sample at time $t$. We use the change in market share as our primary investor preference proxy as Spiegel and Zhang (2013) argue that the more commonly utilized proxy, net flow, fails to consider the effect of aggregate investor allocations when testing the flow-performance relation. Chalmers, Kaul, and Phillips (2013) show that investors react to macroeconomic indicators in unison when allocating flows across mutual fund asset classes. Flow-performance models which fail to control for correlated flows across funds of the same type may be misspecified. To further control for correlated investor allocations across time or fund, when estimating equation (1) we cluster standard errors by fund and date (month-year).

A disadvantage with market share measures is that a fund market share might increase if it holds securities that increase in value even if they do not attract or lose any new investors due to stale return roll off. For example, if a fund holds $30 \%$ of its allocation in IBM and IBM triples in a month, this fund's market share is likely to increase, even absent any new flows. Hence, in

\footnotetext{
${ }^{7}$ To identify actively managed mutual funds, we use the list of actively managed funds from Cremers and Petajisto (2009) available from Antti Petajisto's website http://www.petajisto.net/data.html.
} 
Panel B, we also report the same regression as in equation (1) but using net flow as our dependent measure.

$$
\text { Flow }_{t}=\alpha+\beta_{1} R_{t-1}+\beta_{n} R_{t-n}+\epsilon_{t}
$$

Net flow is defined as: $F \operatorname{low}_{i, t}=\frac{T N A_{i, t}-T N A_{i, t-1} \times\left(1+R_{i, t}\right)}{T N A_{i, t-1}}$ where flow for fund $i$ in month $t$ is calculated as the percentage change in TNA while controlling for return $(R)$ effects. The intuition behind this measure can be illustrated with a simple example. Suppose a fund has a TNA value of $\$ 500$ in period $t$ and its rate of return is $5 \%$ over the coming month. In the absence of any changes in investor behavior, the fund TNA will be $\$ 550$. Hence, a TNA value of $\$ 580$ in period $t+1$ implies that net inflows were $\$ 30$. These net inflows should be subject to stale return chasing, not the increase in TNA, $\$ 50$, due to the return earned by the fund. For robustness, we also replicate our analysis using net sales (sales less redemptions excluding dividend reinvestment) collected directly from fund N-SAR filings and provided by Morningstar.

We note that using the traditional Fama-MacBeth (FM) type regression specification is inappropriate in our analysis. The FM approach assumes serial non-correlation and strong crosssectional correlations. This is plausible when the dependent variable is a return but not when it is an inflow or on outflow.

As previously discussed, to motivate our use of equation (1) and (3), we note that the change in HPR has only two influences, the magnitude of the return in the current period and the magnitude of the end-return which drops from the calculation. These two returns have an equivalent impact on the HPR, though only the former is new information. Modeling investor response to the change in HPR, it then follows that $\Delta m_{t}$ (or Flow $w_{t}$ becomes a function of the new and end-return, linearly approximated by equation (1). All intervening returns are common between adjacent HPRs and have no influence on $\triangle$ HPR. If investors interpret the stale information component of the change in HPR as information regarding future fund performance, we expect the $\beta_{n}$ coefficient related to return observations at the end of standard HPR reporting periods to be negative. This relation follows from the inverse relation between the magnitude of the end return which drops from the sample and the change in the HPR. 


\section{Do investors chase stale returns?}

The $\beta_{n}$ coefficients from the pooled, OLS regression series in equation (1) and associated t-statistics are reported in Panel A of Table I. As discussed, mutual funds are required to report HPRs in set intervals of 1,5 , and 10 years and reporting the 3 year HPR has become convention. Given the length of our sample, we focus on the first three intervals. Thus, the variables of interest in Table I are the magnitudes and signs of the $13^{\text {th }}, 37^{\text {th }}$, and $61^{\text {st }}$ monthly return lag. The first reported t-statistic (Reg. t-stat) tests if the coefficient is significantly different from zero. We note that there are several coefficients, apart from the coefficients of interest, that are also statistically significant (examples include $\beta_{4}, \beta_{6}$, or $\beta_{7}$ ). It is plausible that the random allocation activity of investors causes the coefficients for certain return lags to be different from zero. Hence, we implement a standard placebo test, randomly allocating returns to investor allocation observations with and without replacement and replicate equation (1). In the placebo tests (reported in Table A1 of the online appendix), a similar number of return coefficients are statistically different from zero, reflecting an inherent level of noise in investor preferences and the estimation of their relation with returns. In addition, although we have no specific priors that investors should use other return lags when directing allocations, we do not exclude the possibility that future research will uncover further relations between return lags and investor allocations. The significance of other return coefficients may also reflect these unknown relations. Hence, we also report a difference t-statistic (Diff. t-stat) below the regular t-statistic testing if the return coefficient is different from the absolute mean coefficient, which is the value arising from random allocations by investors. Since the average absolute return coefficient value in Panel A of Table $\mathrm{I}$ is 0.145 , the difference t-statistic tests the null hypothesis $\mathrm{H}_{0}: R_{n}=$ average $\left|R_{n}\right|=0.145$. 
We find that the coefficients related to the $13^{\text {th }}, 37^{\text {th }}$, and $61^{\text {st }}$ return lags are larger than all but one of the other coefficients. ${ }^{8}$ The average absolute value of these three coefficients is 0.35 , twice the size of the absolute mean coefficient (significant at the $5 \%$ level). With the exception of the $R_{t-14}$ and $R_{t-18}$ coefficients, none of the other coefficients are significantly different from both zero and the absolute mean of the coefficient sample $(\alpha=10 \%){ }^{9}$ In particular, the $25^{\text {th }}, 49^{\text {th }}$, and $73^{\text {rd }}$ return lag coefficients, which relate to the 2,4 , and 6 year HPRs, are not significantly different from the absolute mean (t-statistics $1.51,0.41$ and 1.15 , respectively). It is also noteworthy that the magnitudes of return-chasing on the lags of interest are of equal or greater magnitude to return-chasing on the first return lag (the average coefficient value on the first return lag in equation (1) is 0.31 ). Investor asset allocations appear equally or more sensitive to the stale information reflected in HPR end-returns relative to the new information reflected in the most recent return. Our conclusions are qualitatively similar when we use equation (3) using net flow, as an alternative proxy for investor preferences. The coefficients are reported in Panel B. We note that in particular, the $R_{t-14}$ and $R_{t-18}$ coefficients are no longer significantly different from the absolute mean. To provide a sense of economic scale, a one standard deviation shift in $\mathrm{R}_{t-1}, \mathrm{R}_{t-13}, \mathrm{R}_{t-37}$, or $\mathrm{R}_{t-61}$ is associated with a $2.0 \%, 1.7 \%, 2.2 \%$ and $2.7 \%$ shift in flow (net sales or redemptions as a percentage of fund TNA).

It is also noteworthy that some coefficients are consistently negative (though not always significantly different from the absolute mean of the sample). These are typically months right around annual horizons and at semi-annual horizons. For example, $R_{t-6}, R_{t-12}, R_{t-14}, R_{t-18}, R_{t-24}$, and $R_{t-25}$ coefficients are all usually significantly negative. Our results pertain to investor responses to stale returns, not managerial responses. It is likely that there are other significant patterns in past returns that affect investor behavior that we have not isolated. Whether these patterns in investor responses to past returns are related to asset pricing anomalies documented in the literature, is likely to form an interesting extension to this paper.

\footnotetext{
${ }^{8}$ The $R_{t-14}$ is larger than the $R_{t-61}$ coefficient $(-0.29$ versus -0.28$)$ but is smaller than the $R_{t-13}$ and $R_{t-37}(-0.33$ and -0.43 , respectively).

${ }^{9}$ Using an alpha value of $5 \%$, only the $13^{\text {th }}$ and $37^{\text {th }}$ return lags are different from the absolute mean coefficient.
} 
We next implement a series of robustness tests and extensions to the base model, which are reported in Panels $\mathrm{C}$ and $\mathrm{D}$ in Table 1 and in Table A2 of the Online Appendix. As previously discussed, only the most recent return and the end-return which drops from the sample influence the change in HPR and our focus is to determine if investors differentiate between these two sources of changes in HPRs. For this reason, we exclude intervening returns from the stale return-chasing model in Panel A. The alternative hypothesis to stale performance chasing is that investors observe the full time series of returns and make asset allocation decisions after considering all available returns. Under this alternative hypothesis, stale performance chasing should not be observed as the investor can easily decompose the change in HPR into current and stale information components. In Panel $\mathrm{C}$, we replicate Panel A, but estimate the coefficient on each return lag simultaneously in one pooled regression, in essence assuming that investors observe and adjust allocations jointly based on all 73 return lags (equation (4)).

$$
\Delta m_{t}=\alpha+\sum_{n=1}^{73} \beta_{t-n} R_{t-n}+\epsilon_{t}
$$

Our conclusions are unaffected. The coefficient estimates are similar between Panel A and C. The average value of the $\beta_{13}, \beta_{37}$, and $\beta_{61}$ coefficients is -0.34 relative to -0.35 in Panel A. The $R_{t-}$ 14 coefficient is no longer statistically different from the average absolute coefficient in the joint model though $R_{t-6}$ and $R_{t-7}$ become statistically different. We also report a more parsimonious version of equation (4) in Panel D where we also include $R_{t}$ as an additional coefficient, and obtain largely similar results.

The remainder of the extensions and robustness tests are reported in Panel E and in Table A2 of the online appendix. In the interest of brevity, only the coefficients of interest are reported in Panel E (the full output is reported in Table A2). For ease of comparison, coefficients from Panel A are reported in Panel E as model (1). Across all our tests, the $\beta_{13}, \beta_{37}$, and $\beta_{61}$ coefficients are the only coefficients that are consistently significantly different both from zero and the average.

In model (2) we jointly cluster by fund, fund family and time as investor allocations may be correlated at the family level. Clustering on the additional family dimension does not alter our 
conclusions. All three coefficients remain significant at the $1 \%$ level. However, investor allocations are likely to be influenced by a range of factors beyond prior fund performance. In the base specification earlier, controls for investor preferences were not included. This is because if the determinants of stale return chasing are also the determinants of investor preferences, this joint influence will cause our stale performance chasing estimates to be understated. ${ }^{10}$

Cognisant of this potential conflict, in model (3), we replicate equation (1) adding the following controls commonly used in the mutual fund literature (all measured at the end of period $t-1$ ): change in market share, fund TNA, fund age, family TNA, number of funds in the fund family, standard deviation of monthly fund returns over the prior year, expense ratio, portfolio turnover, Morningstar rating, and the change in Morningstar rating. Expense ratio and portfolio turnover are calculated as the percentage of TNA charged as expenses and the percentage of TNA traded per annum, respectively. Overall, our conclusions are unaffected. As expected however, the addition of controls diminishes the size of the stale return chasing coefficients. In particular, the magnitude of the $R_{t-61}$ coefficient decreases from -0.28 to -0.23 and the coefficient is no longer statistically different from the absolute coefficient mean. The $R_{t-13}$ and $R_{t-37}$ retain both their significance and remain statistically different from the absolute mean, the only coefficients to do so. The majority of the shift in the magnitude of the $R_{t-6 l}$ coefficient appears to be caused by including fund expenses and portfolio turnover. Unreported tests show these variables also determine the magnitude of the stale return chasing coefficient from Panel A, causing the stale performance chasing effect to be understated in model (3).

Next, we seek to differentiate between stale performance chasing at the fund and objective level. To do so, we estimate equation (1) with the addition of fund objective fixed effects (model 4). In this model specification, though two of the three coefficients of interest diminish in size, all three coefficients remain statistically different from the absolute mean $(\alpha=10 \%)$. This result suggests that majority of stale performance effect occurs based on fund level and not objective level returns. Jointly augmenting equation (1) to include both objective

\footnotetext{
${ }^{10}$ For example, investors that prefer larger funds may also be more prone to react to stale return signals. Hence including fund size as a control will cause stale performance chasing to be understated.
} 
fixed effects and controls generates coefficients of interest largely on par with the estimates in Panel A (model 5).

It can be argued that seasonal activities undertaken by funds, such as window dressing or dividend payments will bias our estimates. For example, funds predominantly pay dividends in December and the majority of investors instruct the fund to automatically reinvest dividends. ${ }^{11}$ Since CRSP adjusts returns to include dividends, returns are bolstered in December for dividend paying funds and NAV will increase by the reinvested dividend amount. It is important to recognize that our model inherently controls for seasonal effects, as returns are not necessarily calendar aligned as the return series for each fund starts at inception which may occur at any time. Thus, for example, $R_{t-13}$ is not inherently a December return for all funds.

To mitigate concerns related to seasonal effects, we use three approaches. First, we replicate our models after clustering by month. Since our results remain robust to this approach, we do not report these results for brevity. Second, we utilize total sales and redemptions from the N-SAR filings of each fund available from Morningstar. This alternative data source enables the direct calculation of investor preferences (sales - redemptions) from which we exclude reinvested dividends. Using net sales (model 6), the significance of the coefficients of interest improves. Third, we exclude January returns from the sample and replicate the model (Model 7, Table 2A of the Online Appendix) and find similar results.

Finally, we report several specifications in Table A2 in the Online Appendix to answer additional questions. We emphasize that these are largely ad hoc specifications which are not driven by theory. First, do investors react to raw returns or market-adjusted returns? To answer this question, in Model 8, we estimate the model using returns in excess of the return to the SP500 Index. Our results are largely unaffected by this adjustment with this model generating results broadly consistent with model 4 of Panel E in the main paper. Second, is the relation symmetric? In other words, are the results driven only by negative returns dropping from the

\footnotetext{
${ }^{11}$ In the 2011 Factbook, the Investment Company Institute reported that investors reinvested $\$ 173$ out of \$202 billion USD paid in dividends (86\%). Examining the payment period in the CRSP database, $20 \%$ of dividends are paid in December, with remaining dividends spread evenly over the remaining months with the exception of small increases in frequency at the end of calendar quarters.
} 
sample? Coefficient estimates reported in Table A2 Model 9 are estimated after replacing each negative return with 0 , thus eliminating negative returns from the return history. We find significant effects when positive returns are dropped from the sample, implying that the relationship is symmetric. In particular, the $R_{t-13}, R_{t-37}$, and $R_{t-61}$ retain their significance though not surprisingly, given the ad hoc nature of this analysis, a few other variables such as $R_{t-45}$ also become significant. Finally, in Table A2 Model 10, we examine if the effect is non-linear in general. We sort each coefficient of interest $R_{t-13}, R_{t-37}$, and $R_{t-61}$ into terciles and report the $\beta$ coefficients for the three regressions separately. The magnitude of the stale return chasing effect does appear to increase strikingly when the most negative returns drop off from the sample. However, we still find a significant return-chasing relation even when the highest returns drop off from the sample, consistent with the results reported in Model 9.

We note that our results are sensitive to the choice of sub-period. As we discuss below, the prominence to investors of HPR changes is influenced by time varying manager behavior. More importantly, large improvements in HPRs result from large negative returns dropping from the horizon of analysis. HPR changes are hence realized in cascades, with a large negative return dropping from the 1 year horizon first, impacting the 3-year HPR 2 years later and finally affecting the 5-year HPR after an additional two years have passed. For example, consider the period immediately after the dotcom bubble (referred to in the introductory quote). Funds that were exposed to the end of bubble decline in 2002 will not realize 5-year effects in their returns till 2007. Thus, the average effects we report in Table 1 are not realized in all sub-periods but are observed to vary across the time series as a cascade or wave. This may also give the impression of steadily improving performance (see Figure 1 Panel A) and encourage investors to invest.

In sum, these results provide strong evidence of mutual fund investors chasing stale performance. Mutual fund allocations are more sensitive to lagged returns associated with the end of commonly reported HPR periods. These findings are consistent with mutual fund investors observing changes in HPR values and interpreting these changes as new information regarding future fund performance. 


\section{Does fund advertising take advantage of stale return chasing behavior?}

We use two proxies for fund marketing expenditures. First, following Sirri and Tufano (1998), we use the 12b-1 expenditure of the fund. The 12b-1 fee is a noisy proxy. Although described as being levied to cover marketing and distribution expenses, only approximately $2 \%$ is used for promotion or advertising. ${ }^{12}$ Although a relatively small proportion of the $12 \mathrm{~b}-1$ fee is directed at advertising, it is still used in prior research as a reasonable proxy for the general marketing effort of the fund.

Our second proxy for marketing expenditure is investment company advertising data compiled by Kantar Media (KM). KM is an advertising consulting firm which makes available compendiums of advertising activity in all U.S. media outlets. Although KM collects data for all advertising mediums, our data is limited to print media (newspaper and magazine) advertising, which Reuter and Zitzewitz (2006) report accounts for $65 \%$ of total investment company advertising expenditures. The KM dataset includes estimates of advertising expenditures based on advertisement size, placement, and periodical. This data is summarized monthly by investment company and periodical from 2005 to 2010. In addition, for the magazine advertisements, a PDF copy of each advertisement is supplied. A detailed description of the advertising dataset construction process appears in the online appendix. In total, 123 magazines and 3 newspapers appear in the dataset. Examples include common finance periodicals such as the Wall Street Journal, the New York Times, Barron, and Bloomberg Business Week in addition to magazines with other focuses such as Bon Appetit, Coastal Living, or Rolling Stone. 144 unique fund families advertise at least once in the dataset. The magazine portion of the dataset features 2,355 unique advertisements, many featured in multiple magazines over multiple months.

Table II presents summary statistics for the advertising dataset. On average, investment companies spent 264 million USD on print media advertising annually. Spending typically increases annually, on average by $16 \%$ year-over-year, with the exception of 2008 to 2009 when

\footnotetext{
12 The balance is used for advisor initial sales incentives (40\%), ongoing shareholder services (52\%) and underwriting fees (6\%) (ICI, 2005).
} 
advertising expenditures dropped by $31 \%$, coinciding with the start of the mortgage backed security (MBS) crisis. On average, $66 \%$ of advertising expenditures were directed at magazines relative to newspapers. These values are broadly consistent with Reuter and Zitzewitz (2006) who note that, on average, from 1996 to 2002 investment companies spent 199 million USD per year on print media advertising, with a 60:40 proportion between magazines and newspapers.

To provide a sense of the objective of investment company advertising, we partition the magazine advertisements by focus. Investment companies provide a range of products and services in addition to mutual funds, such as exchange traded funds, retirement plans, or other types of investment plans. On average, only $32 \%$ of advertising undertaken by investment companies directly promotes mutual funds. Of the advertising focused on promoting mutual funds, on average, $31 \%$ focused on general promotion of the fund family, while the other $69 \%$ promoted one or more specific funds. $39 \%$ of fund specific advertising promoted the HPR of the featured funds. Rankings by mutual fund rating agencies such as Morningstar, Lipper, or Barron are commonly computed using HPRs over the standardized 1, 3, 5, and 10 year horizons and it is common to provide separate ratings for the same fund based on each horizon. Thus, we separately track advertisements that promote a rating by an analyst that is horizon-specific ( $8 \%$ of fund specific advertising). Of the remaining 53\% of fund specific advertising, $38 \%$ promote the overall rank of the fund by an analyst without reference to the HPR and $15 \%$ promoted other fund features such as fee structure or the fund manager.

The trend of increased spending on advertising from year-to-year is evident in each of these partitions with the noteworthy exception of spending on advertisements that feature HPRs. In 2005, 57\% of fund specific advertising promoted HPRs and this proportion declines throughout the sample, dropping sharply from 2007 to 2009, coinciding with negative market performance associated with the MBS crisis. In 2009, investment companies spent 18 times less money promoting HPR results than in 2005 (28.5 million in 2005 relative to 1.6 million USD in 2009). This trend is consistent with investment companies preferentially advertising HPR information only when performance is strong. 
To more closely examine the determinants of advertising and the influence of HPRs on advertising expenditures, in Table III, we relate the change in annual fund specific advertising expenditures to determinant variables. Ideally, we would run a cross-sectional regression using advertising expenses as our dependent variable and monthly returns as our independent variables. If investment companies were indeed taking advantage of stale return chasing behavior, we would expect that the worse the $t-13, \mathrm{t}-37$, and $\mathrm{t}-61$ returns, the higher advertising expenses would be in period $t$ (companies increase advertising spending when they look better). Unfortunately, advertising data is coarse. Spending by investment companies can go from zero in one month to a large positive number in the next. In addition, advertising is seasonal and the same advertisement is run in multiple magazines over different or the same months. Though the data is reported monthly, the irregularity of the data leads us to implement the same idea on an annual basis. Hence, we compute annual advertising expenses starting from the start date of each fund. If investment firms were taking advantage of stale return chasing behavior, we would expect that the larger the drop off in the $T-4$ and $T-7$ annual returns, the higher the advertising expenses should be in year $T$.

Specifically, we first partition the dependent variable by expenditures that feature HPR information (either actual returns or HPR related rank) and advertising that features analysis recommendation absent of HPR info. Collectively, these two types of advertising represent $85 \%$ of fund level advertising expenditures in our sample. The dependent variables are standardized by fund TNA as advertising expenditures are inherently greater for larger funds (Gallaher, Kaniel, and Starks, 2008). Standard errors are clustered by fund and the models include year fixed effects. ${ }^{13}$

We limit our sample to funds which advertise any time between 2005 and 2010. As shown in Table II, many fund families elect not to advertise HPRs, or for that matter, elect not to advertise at all. We focus on funds which advertise HPRs or analyst rank as our objective is to model the timing decisions and incentives to utilize HPRs as a promotional tool and not the

\footnotetext{
${ }^{13}$ Our results are robust to joint clustering of standard errors by fund and fund family.
} 
underlying decision of whether to advertise or not. For controls, we follow Gallaher, Kaniel, and Starks (2008) who find that performance over the prior year, family size, loads, fees, portfolio turnover, Morningstar rating, flow, and flow volatility influence annual family-level advertising expenditures. To this list, we add market return as Mullainathan and Shleifer (2005) find that funds are more prone to advertise performance results during periods of strong market performance, regardless of the relative performance of the fund. We also include fund age, as young funds may be more likely to advertise to increase investor awareness.

We focus first on advertising that reports HPR related information, either the actual return or analyst rating by holding period (Panel A). In models (1) - (3) of Table III, we find that funds spend more money advertising HPRs the year after the 1, 3, and 5 year HPRs are individually higher (average t-statistic 3.54), consistent with funds seeking to draw attention to prior strong performance. ${ }^{14}$ In economic terms, an increase of one standard deviation of 1, 3, and 5 year HPRs individually increases advertising spending by $\$ 421,006, \$ 526,257$, and $\$ 799,911$ respectively. The significance of each HPR coefficient is retained when the three HPRs are considered jointly (models (4)). Collectively, an increase of one standard deviation in all three HPRs increases advertising spending by $\$ 1,473,520$. These values are relative to average annual spending on HPR advertising of approximately 15 million dollars. Thus, a joint one standard deviation shift in all three coefficients results in a $10 \%$ shift in advertising expenditures.

We next seek to differentiate between advertising current relative to stale performance. Specifically, we seek to understand the source of the relative size of the HPR advertised by mutual funds, i.e. is the HPR high due to positive recent performance or due to the passage of time and weak prior performance dropping from the sample? To make this distinction, we partition the sample into quartiles by the 1 year HPR which dropped from the sample (i.e. the $H P R_{T-4}^{1 Y e a r}$ or $H P R_{T-6}^{1}$ Year for the 3 and 5 year HPR, respectively). The two middle quartiles are aggregated to form three partitions. If funds are preferentially advertising stale performance, we

\footnotetext{
${ }^{14}$ To ensure clarity in our notation, $H P R_{t-1}^{3 \text { Year }}$ refers to the 3 year HPR calculated using monthly returns and ending in year $t-1$.
} 
expect greater spending on HPR advertising when the return which dropped from the sample is small (more negative), resulting in an increase in the reported HPR.

We find that funds indeed spend a greater amount on HPR related advertising when reported HPRs are higher due a low return dropping from the horizon of assessment. Specifically, the average coefficient on the 1, 3 and 5 year HPR is 0.29 in the bottom quartile of the $H P R_{T-4}^{1}$ Year relative to an average value of 0.07 in the top quartile (a fourfold difference). The magnitude of the difference is similar for the $H P R_{T-6}^{1}$ Year partition models. Since funds are required to jointly advertise the 1,5 , and 10 year HPRs and, by convention, also typically report the 3 year HPR, the coefficient sizes across the 1, 3, and 5 HPR variables are similar. This result suggests that funds make HPR related advertising decisions jointly evaluating the four reported HPRs. They also suggest a strong preference to advertise stale performance effects on HPRs by mutual funds.

These results are not entirely unexpected. Improvements in HPRs due to poor performance dropping from the horizon of assessment are likely easier to predict than improvements due to immediate past performance. Hence, funds are better able to systematically plan advertising campaigns around stale performance related improvements in HPRs than recent performance improvements. In Panel B of Table III, we replicate the tests using fund advertising that includes analyst rating information excluding HPR references as the dependent variable. Our results are highly similar, suggesting that funds interchangeably use analyst and HPR related advertising to draw attention to the fund when the fund has benefited from an increase in performance. We hypothesize that the underlying decision to utilize HPR advertising relates to investor sensitivity to HPRs and explore this thesis in greater detail below.

Turning briefly to the control variables, funds from larger fund families tend to spend more on HPR advertising. Younger funds typically spend smaller amounts advertising HPRs, perhaps due to the limited performance history available for younger funds. Fund families typically promote funds with lower flows and higher flow standard deviations, higher expense ratios and front end loads, and funds with higher Morningstar ratings which realize an increase in 
Morningstar rating. Back end loads and portfolio turnover are not significant determinants of HPR advertising expenditures.

\section{What does stale performance chasing depend on?}

\subsection{Cross-sectional determinants}

To explore the determinants of stale performance chasing at the fund-level, we estimate equation (1) by fund and year, producing an annual time series of $\beta_{n}$ coefficients for each fund. We then relate the fund-level $\beta_{13}, \beta_{37}$, and $\beta_{61}$ coefficient time series to determinant variables using a pooled, cross-sectional panel to test a series of hypotheses. As in prior models, we include time fixed effects and cluster standard errors by fund. As the dependent variable is an estimated quantity from equation (1), to correct for heteroskedasticity induced by variance in the observations of the dependent variable, we follow Lewis and Linzer (2005) and calculate tstatistics utilizing White (1980) heteroskedastic consistent standard errors.

Our fund visibility hypotheses assume an environment of heterogeneously informed investors who must choose among a large number of fund alternatives. ${ }^{15}$ As argued in Sirri and Tufano (1998), search costs are high, both due to the number of alternatives which need to be evaluated and the large amount of information provided by a variety of outlets. We distinguish between mutual fund supplied information (advertising) and external fund visibility (where the fund is visible for reasons other than fund supplied advertising). This division is motivated by Huang, Wei, and Yan (2007) who document differential performance chasing by investors of funds with greater "passively available" information such as funds from large families which greater information distribution services. ${ }^{16}$ Large funds are more likely to be covered in the popular press, implying that fund supplied advertising is likely to be less important for these funds. We argue that less sophisticated investors, who are unable to differentiate between funds

\footnotetext{
${ }^{15}$ In this context, the information set available to each investor is largely homogeneous. Heterogeneity arises from variation in investor ability to effectively synthesize and analyze information as a result of sophistication and time constraints.

${ }^{16}$ Huang, Wei and Yan (2007) differentiate between passively available information available via the media or brokers which arrives with minimal effort by the investor relative to actively available information for which the investor must exert effort and seek out.
} 
based on more relevant factors, will select funds which reduce search costs via visibility. This effect is likely to be lower for funds with high external visibility. These expectations are broadly consistent with relations noted by Kaniel, Starks, and Vasudevan (2008) who find that the effects of media coverage on fund flow is greater for younger funds which they argue have lower inherent external visibility.

Hypothesis 1: Mutual funds which advertise more broadly, and especially mutual funds that advertise HPR information, are more likely to attract investors prone to react to artificial performance trends in HPRs. The effect is likely to be lower for mutual funds which are more visible due to their size or the size of their fund family or for funds for which a longer return history is available.

The regression analysis in this portion of the paper is limited to the $2005-2010$ period due to the limitations of advertising data availability. Our proxies for external fund visibility include fund size (TNA), age, the number of funds in the mutual fund family, and uncertainty in fund value (proxied by mutual fund return standard deviation). Our proxies for fund supplied visibility include the marketing and advertising expenses for the fund (described in the previous section).

We partition mutual fund advertising into three segments at the family level: 1) nonmutual fund advertising, 2) mutual fund advertising that is not fund specific and 3) mutual fund advertising that is fund specific. Fund specific advertising is then divided into advertising the fund of interest or a different fund. Advertising that features the fund of interest is finally divided into 1) ads which include HPR info (either actual return or analyst ratings by HPR horizon), 2) ads that include analyst rating but no HPR info and 3) ads that do not include either HPR or analyst ratings.

Recall that a more negative $\beta_{n}$ reflects more pronounced stale performance chasing. In Table IV, we document results that are broadly consistent across the three return-chasing coefficients. Stale performance chasing tends to be lower for larger (greater TNA) and older funds and funds from larger families (greater family TNA). Funds from families which offer a larger number of funds also tend to have less return-chasing, though the relation is not significant 
at conventional levels. Stale performance chasing tends to be higher for funds with greater value uncertainty as proxied by the standard deviation of mutual fund returns over the prior year. These results are consistent with Hypothesis 1: funds that are externally visible to investors are less prone to stale performance chasing as information search costs for these funds are lower and more relevant decision factors can more easily be obtained.

We next examine the effect of fund marketing on stale performance chasing. Funds with higher $12 \mathrm{~b}-1$ expenditures typically realize more pronounced stale return-chasing. The relation is significant when considered jointly with the advertising expenditure proxies, suggesting that $12 \mathrm{~b}-1$ fees capture a unique aspect of the fund marketing effort which renders the fund more visible. One potential channel is via broker sales as $12 \mathrm{~b}-1$ fees are commonly utilized to create inducements for brokers to sell funds.

Advertising broadly increases stale performance chasing, both at the fund and familylevel. First, focusing on family-level partitions, non-mutual fund related advertising has little effect on the magnitude of false return chasing, an unsurprising result. However, general mutual fund advertising at the family level induces a stronger investor response to stale performance trends (negative and significant Family Mutual Fund Ad Spending coefficient). Turning to fund specific advertising, ads which report HPR info induce the largest investor response to stale performance signals, followed by advertising that features analyst ratings. The magnitude of the response of investors to ads that feature HPR info is typically twice that of ads that feature analyst rating with no reference to HPR info. The sensitivity of stale performance chasing to ads featuring analyst rating likely arises from the timing of such advertising, which we show in Table III to coincide with end-return related improvements in HPRs. Fund specific advertisements that promote another fund or mention neither HPRs or analyst rating have no significant effect on stale performance chasing, which is perhaps surprising given the otherwise broad evidence that non-fund specific advertising typically generates greater stale performance chasing. This result is, however, consistent with investors typically reacting more strongly to HPR advertisements. The strongest inducement for investors to chase stale performance is typically fund specific advertising that mentions horizon specific information. 
We also consider an alternative form of fund promotion not undertaken by the fund, but provided by Morningstar via its star ratings. Morningstar ratings are based on performance over the prior 3, 5, and 10 years, adjusted for risk based on variation in the fund's monthly performance, placing emphasis on downward variations. ${ }^{17}$ As Morningstar ratings are determined largely based on HPRs, improvements in star ratings are likely to coincide with periods when stale performance effects are realized. At that time, the ranking method emphasizes return persistence resulting from the reduction of negative (or lower relative) monthly returns over each horizon. Thus, the Morningstar rating system draws attention to HPR over the same horizons commonly advertised by mutual funds and may be an alternative determinant of stale performance chasing. Prior analysis has shown that investors respond to Morningstar ratings, apparently perceiving them to be an indicator of manager skill. For example, Del Guercio and Tkac (2008) document that changes in Morningstar ratings generate abnormal flow following both upgrades (positive flow) and downgrades (negative flow). ${ }^{18} \mathrm{We}$ find that funds more highly ranked by Morningstar or that have realized an improvement in Morningstar rating are associated with greater stale performance chasing and the effect is of similar magnitude to advertising undertaken by the fund itself.

As a final test of the cross-sectional determinants of stale return chasing, we examine the extent to which the phenomenon varies by investor sophistication. Sophisticated investors should understand the mechanical influence of time on HPRs and recognize that HPR signals provide no new information in excess of the most recent return observation. As a proxy for investor sophistication, we contrast retail with institutional funds (as reported in the CRSP database). Institutional funds are marketed to high net worth individuals and large pension funds managed by professionals who are often viewed as being more sophisticated than retail investors. Across all three stale return horizons we find that, if anything, institutional investors are more prone to stale return chasing than retail investors. The coefficient on the institutional fund indicator is

\footnotetext{
${ }^{17}$ See "The Morningstar Rating for Funds" 2008 factsheet.

${ }^{18}$ See also Kraussl and Sandelowsky (2007) who examine the predictive performance of Morningstar ratings over a ten-year period and conclude they have limited predictive ability of future performance and the predictive ability of the ratings worsens after changes to the rating methodology in 2002. Blake and Morey (2000) find similar results.
} 
negative in all three models and is significantly lower in model (2). Our results on stale performance chasing are similar to those of Alti, Kaniel, and Yoeli (2006) who document returnchasing in an institutional subset of funds. In addition, Salganik (2012) finds no distinction in fund selection ability between retail and institutional investors.

We next undertake a series of unreported robustness checks. First, we replicate our analysis augmenting the model with objective fixed effects and additionally clustering standard errors by fund family. As in Table I, addition of objective fixed effects does not notably alter the size of the coefficient estimates, suggesting that stale return chasing occurs primarily in response to fund and not objective level returns.

Second, to control for endogenous fund characteristics to which investors are alternatively reacting, we use two alternative model specifications. We replicate the analysis adding the other two return-chasing coefficients not considered, as independent variables. For example in the $\beta_{13}$ regressions, we add $\beta_{37}$ and $\beta_{61}$ as independent variables. We hypothesize that if investors are reacting to endogenous factors, these factors are likely to be consistent across the 3 return-chasing coefficients and will thus be reflected in commonalities in those coefficients. ${ }^{19}$ In addition, we replicate the analysis excluding funds which undergo a manager change, as the timing of this change may coincide with improvements in HPR. Our results are robust to both alternative model specifications.

Finally, we replicate the tests using $\beta_{25}$ and $\beta_{49}$ as dependent variables. Advertising expenditures should have little explanatory power for return-chasing coinciding with nonstandard reporting horizons. Consistent with this expectation, we find an insignificant relation between the $\beta_{25}$ and $\beta_{49}$ coefficients and advertising expenditures with one exception. Advertising which promotes a specific fund and reports HPR results is significantly related to stale performance chasing in these two non-standard horizons. However, the magnitude of these coefficients is typically one third the size of the coefficients for the standard horizons $\left(\beta_{13}, \beta_{37}\right.$,

\footnotetext{
${ }^{19}$ The average correlation between the return-chasing coefficient pairs is 0.26 , suggesting that each coefficient reflects unique stale performance chasing episodes and do not reflect endogenous fund characteristics to which investors are reacting.
} 
and $\beta_{61}$ ), consistent with spillover effects. For example, investors may be enticed to invest in the fund in a prior period when standard HPR results are advertised and increase their positions following positive returns in subsequent periods.

To summarize our results, flow sensitivity to stale performance effects appears to be largely driven by the magnitude of marketing effort either at the fund or the family-level. Funds that advertise more broadly, and particularly funds that advertise favorable horizon specific results, realize significantly greater inflows following favorable stale performance chasing signals. Stale performance chasing is similarly greater if the HPRs of the fund are indirectly promoted via the Morningstar rating system or broker sales (proxied by $12 \mathrm{~b}-1$ fees). Funds with higher star ratings are more prone to stale performance chasing behavior by investors. These effects are attenuated if the fund is already externally visible to investors due to its size, age, or the size of the fund family. Stale return chasing is consistent across investor sophistication profiles, providing support for the effect arising due to investor inattention as opposed to naivety reasons.

\subsection{Time series determinants}

We next turn to time series trends in stale performance chasing to examine how market conditions affect the propensity of investors to react to stale performance. If stale performance chasing is undertaken by unsophisticated investors faced with high search costs, then periods of heightened uncertainty in financial markets should relate to higher flow sensitivity to stale performance chasing signals. We base this hypothesis on the findings of Sirri and Tufano (1998) and others who show that less sophisticated investors make allocation decisions based on raw, as opposed to market or risk adjusted returns. Thus, during market downturns and periods of uncertainty, search costs increase as identification of a positive performing fund on a raw basis becomes more difficult. 
Hypothesis 2a: During periods of heightened investor uncertainty in financial markets, search costs increase and investors become more likely to react to noninformative stale performance chasing signals.

Hypothesis 2b: Advertising acts to reduce search costs. During periods of heightened investor uncertainty in financial markets, funds which advertise HPR results should realize incremental greater flow sensitivity to stale performance chasing signals.

As proxies for financial market conditions we use: 1) the VIX volatility index maintained by the Chicago Board Option Exchange and 2) National Activity Index (CFNAI) produced by the Chicago Federal Reserve. Our motivation for the selection of these proxies is to include salient, real economy proxies easily observable by retail investors. CFNAI is the first principal component of 85 monthly series that come from the broad categories of production and income, employment and hours, consumption and housing, and sales, orders and inventories. It includes most of the series we would think of as being important indicators of current economic conditions (e.g. industrial production and unemployment). Similarly, the VIX captures implied volatility amongst the S\&P 500 index constituent firms which proxies for aggregate financial market uncertainty.

The results of the time series determinants of stale performance chasing appear in Table V. In these models, we include as controls the non-advertising related proxies for fund exposure but in the interest of brevity, suppress the coefficient values for the controls. Focusing first on the economic condition proxies, during periods of financial market uncertainty (high values of VIX and low value of CFNAI), flow sensitivity to stale performance chasing signals increases. The coefficients on the interaction of fund specific advertising which includes horizon specific information with the financial market condition proxies are negative and significant. Similarly, funds which feature analyst rating induce incremental stale return chasing during periods of uncertainty. The coefficients on the interaction of fund specific advertising without horizon 
specific data or analyst rating with the financial market condition proxies are all insignificant. To summarize these results, in times of uncertainty in financial markets, investors are more likely to respond to non-informative stale performance chasing signals and these effects are incrementally more pronounced for funds which advertise HPR results or analyst rating during times of stress in financial markets. Again we implement the same series of robustness tests and our conclusions are unaffected.

\section{Do mutual funds change their fees to take advantage of stale performance chasing?}

Our final analysis examines the implications of stale performance chasing for investors. To an extent, some of the implications of stale performance chasing behavior are already well understood. Regardless of whether investors are reacting to contemporaneous or lagged performance signals, as shown by Berk and Green (2004) and Chen et al. (2004), as assets under management expand, economies of scale diminish resulting in a decline in performance with fund size. Lou (2012) similarly documents significant and temporary price impacts of flowinduced trading across mutual funds, which reverse in subsequent years. However, other implications may exist beyond scale effects. Mutual fund fees are set in a competitive environment. Funds that wish to increase fees are likely to time the increase to special situations. For example, Bris, Gulen, Kadiyala, and Rau (2006) show that mutual funds choose to raise fees at points in time when they close their funds to new investors. Thus, beyond the understood performance implications, stale performance chasing may provide mutual funds with the opportunity to increase fees, in essence cashing in on the mechanical effects of HPRs.

To test this hypothesis, we relate fees to our return-chasing estimates. Following Khorana, Servaes, and Tufano (2009) who examine the determinants of mutual fund fees around the world, in these models we include as controls: 1) fund and family-level visibility proxies including size, age and the number of funds in the family, 2) fund change in market share and performance as funds and families with stronger performance and asset inflows are in a stronger 
competitive position to charge higher fees, 3) fund fees, 4) fund market share standard deviation as a proxy for fund value uncertainty and 5) the aggregate TNA of the funds in the same objective classification as a proxy for the level of competition between funds with a given management strategy. Fund and family performance is measured using Fama and French (1993) and Carhart (1997) 4-factor alphas, with family performance measured as the average alpha to all equity funds in the family. The results are reported in Table VI.

We use two return-chasing measures. The first is calculated as in equation (1) but using fund return in excess of the objective value-weighted mean return (Excess $\beta_{n}$ ). The second is calculated by relating aggregate change in market share to all funds in objective $j$ to the objective $j$ value-weighted mean return (Objective $\beta_{n}$ ). These separate return-chasing measures allow us to differentiate between idiosyncratic and objective based return-chasing effects of fees.

Focusing first on the \%Fee regressions in Panel A of Table VI, we find that funds with higher stale return-chasing in the prior period typically charge higher fees as a percentage of TNA. The magnitude of the effect is similar between fund and objective-level stale return signals. On average, a 1 standard deviation increase in return-chasing (Excess $\beta_{n}$ ) across the three models is associated with a $10.5 \%$ increase in fees. A joint 1 standard deviation shift in Excess $\beta_{n}$ and Objective $\beta_{n}$ is associated with a $20.1 \%$ increase in fees. Turning briefly to the controls, funds with higher alphas, higher investor allocations (proxied by change in market share) and higher Morningstar ratings typically charge higher fees. Fund size and family size is typically related to lower fees, consistent with size being related to stronger governance (Guercio, Dan and Partch, 2003).

Although contractual fees are typically time invariant and may only be changed with shareholder consent, mutual funds routinely voluntarily waive fees during periods of poor performance in order to retain performance-sensitive investors (Christoffersen, 2001). To test this channel, we obtain fee waiver data from Morningstar, which reports the percentage of TNA waived from fees in a given year. We then relate the change in waived fees to the stale performance chasing estimates and control variables (models (4) to (6)). The stale performance chasing coefficients are all positive and significant, suggesting that funds reduce waived fees on 
the heels of stale performance chasing flow. The absolute sizes of the coefficient estimates across the model sets are highly similar, suggesting that adjustment to waivers explains the majority of the change in fees associated with stale performance chasing. Thus, our results suggest a channel by which managers are able to realize opportunities to return fees to prior levels without having to generate exceptional returns, i.e. by waiting for mechanical increases in HPRs realized as time passes.

The results in Panel A of Table VI suggest that mutual fees are higher for mutual funds held by more stale return-sensitive investors. We next explore a more direct linkage between HPRs and mutual fund price setting. In Panel B, we replicate the models from Panel A, relating the change in fund waivers to HPRs over the 1, 3 and 5 year horizon. The same set of control variables is included in Panel B, but we do not report the coefficients in the interest of brevity. Focusing first on the full model, we find an inverse relation between the change in waivers and HPRs at all three horizons, suggesting waivers decrease following increases in reported returns. As in Table III, we then partition the models by $H P R_{T-4}^{1}$ Year $_{\text {or }} H P R_{T-6}^{1}$ Year (the end-return that drops from the three and five year HPR, respectively). We expect that fee increases will be incrementally higher when the improvement in HPR results from relatively lower end-returns dropping from the horizon of analysis. This relation would be consistent with funds taking advantage of incremental fund demand resulting from end-return related improvements in HPRs which have been made more visible to investors via advertising. Consistent with this thesis, we find statistically significant differences in the magnitude of waiver decreases associated with end-return related HPR increases. For both the three and five year HPR, fee increases are higher when investor demand is driven by stale as opposed to recent performance.

To summarize these results, we document a channel by which mutual funds exploit naïve or inattentive investors, benefiting from their inability to differentiate between the stale and current information components which jointly influence the change in HPR. Stale return chasing creates investor demand, in turn, creating opportunities for annulation of previously offered fee waivers. The resultant realized fees increase harms current investors who pay higher fees to hold the same fund. Quantifying harm to naïve investors who are enticed to purchase the fund via 
uninformative persuasion is more difficult, as the counterfactual performance of the investment they would have alternatively held cannot be observed. Unreported results suggest that the performance of funds affected by high stale return chasing is not significantly different from other funds, after controlling for fees, fund size and portfolio turnover (all underperform the market on average). However new investors also pay higher fees to hold the same fund. As previously discussed, all holders of the fund are also exposed to greater potential diseconomies of scale with its related drag on performance.

\section{Conclusions}

In this paper, we investigate if horizon effects in reported performance affect investor allocations to mutual funds. Specifically, we examine changes in reported HPR values in mutual fund advertisements. Changes in HPRs are equally influenced by the most recent return which enters and the end-return which drops from the horizon of the HPR calculation. Thus, as time passes, prior poor performance mechanically drops from the horizon of the HPR sample, potentially creating the misperception of improved fund performance.

Our analysis suggests that investors fail to recognize the effect of horizons on HPR calculations, allocating disproportionate wealth to funds when negative stale performance drops from the horizon. Stale performance chasing is more pronounced in fund families that advertise HPR information and is more prevalent during periods of stress and uncertainty in financial markets. Fund families that advertise HPR information during these periods realize incrementally greater stale performance chasing behaviour. Either due to naivety or limited attention, investors misinterpret changes in HPRs, failing to distinguish between the relevant and stale information components of reported performance.

Finally, we show that mutual funds appear to time fee increases to coincide with periods of stale performance chasing, taking advantage of unsophisticated investors who do not appreciate the mechanical effect of time on HPRs. Our results suggest that the form in which 
mutual fund performance is advertised and resultant horizon effects are important influences of investor behavior. 


\section{References}

Alti, Aydogan, Ron Kaniel, and Uzi Yoeli, 2006, Why do institutional investors chase return trends?, unpublished working paper, University of Texas.

Amir, Eli, 1993, The market valuation of accounting information: The case of postretirement benefits other than pensions, The Accounting Review 68, 703-724.

Barber, Brad, Terrance Odean, and Lu Zheng, 2000, The behavior of mutual fund investors, Unpublished working paper, University of California at Davis.

Barber, Brad, Terrance Odean, and Lu Zheng, 2005, Out of sight, out of mind: The effects of expenses on mutual fund flows, Journal of Business, 78, 2095-2120.

Berk, Jonathan, and Rick Green, 2004, Mutual fund flows and performance in rational markets, Journal of Political Economy, 111, 1269-1295.

Bertrand, Marianne, Dean Karlan, Sendhil Mullainathan, Eldar Shafir, and Jonathan Zinman, 2010, What's advertising content worth? Evidence from a consumer credit marketing field experiment, Quarterly Journal of Economics, 125, 263-306.

Blake, Christopher and Matthew Morey, 2000, Morningstar ratings and mutual fund performance, Journal of Financial and Quantitative Analysis 35, 451-486.

Bloomfield, Robert J., 2002, The "incomplete revelation hypothesis" and financial reporting, Accounting Horizons, 16, 233-243.

Bris, Arturo, Huseyin Gulen, Padma Kadiyala, and P. Raghavendra Rau, 2007, Good stewards, cheap talkers, or family men? The impact of mutual fund closures on fund managers, flows, fees, and performance," Review of Financial Studies, 20, 953-982.

Carhart, Mark, 1997, On persistence in mutual fund performance, Journal of Finance, 52, 57-82

Chalmers, John, Aditya Kaul, and Blake Phillips, 2013, The wisdom of crowds: Mutual fund investors' aggregate asset allocation decisions, Journal of Banking and Finance, 37, 33183333.

Chen, Joseph, Harrison Hong, Ming Huang, and Jeffrey D. Kubik, 2004, Does fund size erode mutual fund performance? The role of liquidity and organization, American Economic Review, 94, 1276-1302.

Chevalier, Judith and Glenn Ellison, 1997, Risk taking by mutual funds as a response to incentives, Journal of Political Economy, 105, 1167-1200.

Christoffersen, Susan, 2001, Why do money fund managers voluntarily waive their fees?, Journal of Finance, 56, 1117-1140. 
Cooper, Michael J., Huseyin Gulen, and P. Raghavendra Rau, 2006, Changing names with style: Mutual fund name changes and their effects on fund flows, Journal of Finance, 60, 28252858

Cremers, Martijn and Antti Petajisto, 2009, How active is your fund manager? A new measure that predicts performance, Review of Financial Studies 22, 3329-3365.

Del Guercio, Diane and Paula Tkac, 2008, Star power: The effect of Morningstar ratings on mutual fund flow, Journal of Financial and Quantitative Analysis 43, 907-936.

Del Guercio, Diane, Larry Dan and Meagan Partch, 2003, Governance and boards of directors in closed-end investment companies, Journal of Financial Economics 69, 111-159.

Fama, Eugene F. and Kenneth R. French, 1993, Common risk factors in the returns of stocks and bonds, Journal of Financial Economics 33, 3-56.

Fiske, Susan, 1995, Social cognition, In: Tesser, A. (Ed.), Advanced Social Psychology. McGraw-Hill, New York, pp. 149-194.

Fiske, Susan and Shelly Taylor, 1991, Social Cognition, $2^{\text {nd }}$ Edition, McGraw-Hill, New York

Gallaher, Steven, Ron Kaniel, and Laura T. Starks, 2008, Advertising and mutual funds: From families to individual funds, working paper, University of Texas.

Goyal, Amit and Sunil Wahal, 2013, Is momentum an echo?, unpublished working paper, University of Arizona.

Hand, John, 1990, A test of the extended functional fixation hypothesis, The Accounting Review $65,740-763$.

Heston, Steven L., and Ronnie Sadka, 2008, Seasonality in the cross-section of stock returns, Journal of Financial Economics 87, 418-445.

Heston, Steven L., and Ronnie Sadka, 2010, Seasonality in the cross section of stock returns: the international evidence, Journal of Financial and Quantitative Analysis 45, 1133-1160.

Hirshleifer, David, and Siew H. Teoh, 2003, Limited attention, information disclosure, and financial reporting, Journal of Accounting and Economics, 36, 337-386.

Huang, Jennifer, Kelsey Wei and Hong Yan, 2007, Participation costs and the sensitivity of fund flows to past performance, Journal of Finance 62, 1273-1311.

Investment Company Institute (ICI), 2005, How funds use 12b-1 fees, Fundamentals, Investment Company Institute Research Brief, Vol. 14, No. 2. 
Ippolito, Richard, 1992, Consumer reaction to measures of poor quality: Evidence from the mutual fund industry, Journal of Law and Economics 35, 45-70.

Jegadeesh, Narasimhan, 1990, Evidence of predictable behavior of security returns, Journal of Finance 45, 881-898.

Kahneman, Daniel and Amos Tversky, 1973, On the psychology of prediction, Psychological Review 80, 237-251.

Karceski, Jason, 2002, Returns-chasing behavior, mutual funds, and beta's death, Journal of Financial and Quantitative Analysis, 37, 559-594.

Khorana, Ajay, Henri Servaes, and Peter Tufano, 2009, Mutual fund fees around the world, Review of Financial Studies 22, 1279-1310.

Kraussl, Roman and Ralph Sandelowsky, 2007, The predictive performance of Morningstar's mutual fund ratings, University of Amsterdam working paper.

Lewis, Jeffrey and Drew Linzer, 2005, Estimating regression models in which the dependent variable is based on estimates, Political Analysis 13, 345-364.

Li, Feng, 2008, Annual report readability, current earnings, and earnings persistence, Journal of Accounting and Economics 45, 221-247.

Lou, Dong, 2012, A flow-based explanation for return predictability, Review of Financial Studies, 25, 3457-3489.

Lynch, Anthony W., and David K. Musto, 2003, How investors interpret past fund returns, Journal of Finance, 58, 2033-2058.

Mullainathan, Sendhil, and Andrei Shleifer, 2005, Persuasion in finance, unpublished working paper, Harvard University.

Mullainathan, Sendhil, Joshua Schwartzstein, and Andrei Shleifer, 2008, Coarse thinking and persuasion, Quarterly Journal of Economics, 123, 577-619.

Palmiter, Alan R., and Ahmed E. Taha, 2012, Mutual fund performance advertising: Inherently and materially misleading?, Georgia Law Review 46, 289-.

Pumlee, Marlene, 2003, The effect of information complexity on analysts' use of that information, The Accounting Review 78, 275-296.

Reuter, Jonathan, and Eric Zitzewitz, 2006, Do ads influence editors? advertising and bias in the financial media, Quarterly Journal of Economics, 121, 197-227. 
Salganik, Galla, 2012, The "smart-money" effect: Retail versus institutional mutual funds, Unpublished working paper, Ben-Gurion University.

Sirri, Erik R. and Peter Tufano, 1998, Costly search and mutual fund flows, Journal of Finance, $53,1589-1622$.

Spiegel, Matthew, and Hong Zhang, 2013, Mutual fund risk and market share-adjusted fund flows, Journal of Financial Economics 108, 506-528.

White, Halbert, 1980, A heteroskedasticity-consistent covariance matrix estimator and a direct test for heteroskedasticity, Econometrica 48, 817-838. 
Table I

\section{Stale Performance Chasing Measurement}

This table reports the return-chasing coefficient $\left(\beta_{n}\right)$ from the series of 72 separate pooled OLS regressions: Panel A and C: $\Delta m_{t}=\alpha+\beta_{1} R_{\text {Return }} n_{t-1}+\beta_{n} R_{e t u r n} n_{t-n}+\varepsilon_{t}$ and

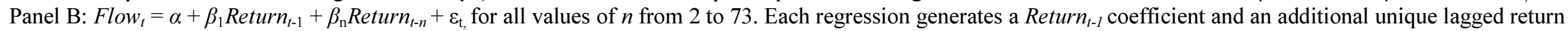

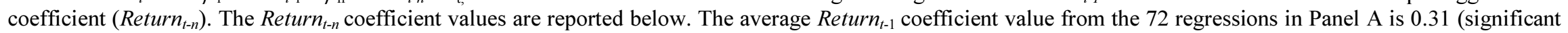
at the $1 \%$ level). Two $t$-statistics are reported. The first (Reg.t-stat) tests the null $\mathrm{H}_{0}: \beta_{n}=0$. The second (Diff. t-stat) tests the null $\mathrm{H}_{0}: \beta_{n}=\sum_{2}^{73}\left|\beta_{n}\right|$. T-test statistics are clustered by fund and date (month-year). In Panels A and C, the dependent variable $m_{t}$, is market share defined as mutual fund total net assets (TNA) divided by the total TNA of all funds in the sample in month $t$. In Panel $\mathrm{B}$, the dependent variable is the percentage growth in mutual fund total net assets (TNA), defined as: (TN $A_{i, t}-T N A_{i, t-}$ ${ }_{l} \times\left(1+\right.$ Return $\left.\left._{i, t}\right)\right) / T N A_{i, t-l}$ in month $t$ for fund $i$. The sample includes all domestic, actively managed mutual funds in the U.S. between 1992 and 2010 . Return coefficients coinciding with the end of commonly reported holding period returns (1,3, and 5 years) appear in bold face. The output for all 72 regressions are reported in Panels A-C. Panel D tests a parsimonious version of Panel C. In the interest of brevity, in Panel E only the coefficients of interest are reported (the full output is available in the online appendix to the paper). In Panel C, the return coefficients are estimated simultaneously in one model. In Panel E, in addition to market share, an additional proxy for investor preferences used in model 6: N-SAR net sales calculated as the difference between share sales and redemptions reported directly by the fund in form NSAR. Controls included in select models in Panel E include log fund TNA, log fund age measured from the date of fund inception to the start of the year of $\beta_{n}$ estimation, log number of funds offered by the investment company (family) of the fund, log total family TNA, fund return standard deviation calculated over the prior year based on the fund's monthly returns, Morningstar rating, the change in Morningstar rating, portfolio turnover measured as the percentage of average total net assets traded in year $t$, and expense ratio measured as the percentage of total net assets which investors pay for the fund's operating expenses.

Panel A: Base Model with market share

\begin{tabular}{|c|c|c|c|c|c|c|c|c|c|c|c|c|}
\hline & $\mathrm{R}_{\mathrm{t}-2}$ & $\mathrm{R}_{\mathrm{t}-3}$ & $\mathrm{R}_{\mathrm{t}-4}$ & $\mathrm{R}_{\mathrm{t}-5}$ & $\mathrm{R}_{\mathrm{t}-6}$ & $\mathrm{R}_{\mathrm{t}-7}$ & $\mathrm{R}_{\mathrm{t}-8}$ & $\mathrm{R}_{\mathrm{t}-9}$ & $\mathrm{R}_{\mathrm{t}-10}$ & $\mathrm{R}_{\mathrm{t}-11}$ & $\mathrm{R}_{\mathrm{t}-12}$ & $\mathbf{R}_{\mathrm{t}-13}$ \\
\hline Coef. & 0.09 & 0.10 & 0.16 & 0.08 & -0.26 & 0.26 & 0.07 & 0.17 & 0.06 & 0.11 & -0.19 & -0.33 \\
\hline Reg. t-stat & 1.40 & 1.52 & 2.24 & 1.32 & -3.14 & 3.19 & 1.01 & 2.37 & 0.86 & 1.67 & -2.79 & -4.11 \\
\hline Diff. t-stat & -0.80 & -0.73 & 0.25 & -0.98 & 1.35 & 1.39 & -1.16 & 0.32 & -1.15 & -0.58 & 0.66 & 2.30 \\
\hline $\mathrm{N}$ & 425,781 & 423,464 & 421,101 & 418,218 & 415,466 & 413,988 & 411,269 & 408,523 & 405,527 & 402,662 & 400,511 & 397,586 \\
\hline \multirow[t]{2}{*}{ Adjusted $\mathrm{R}^{2}$} & $24.85 \%$ & $24.64 \%$ & $24.41 \%$ & $24.18 \%$ & $23.94 \%$ & $23.76 \%$ & $23.58 \%$ & $23.46 \%$ & $23.34 \%$ & $23.21 \%$ & $23.04 \%$ & $22.85 \%$ \\
\hline & $\mathrm{R}_{\mathrm{t}-14}$ & $\mathrm{R}_{\mathrm{t}-15}$ & $\mathrm{R}_{\mathrm{t}-16}$ & $R_{t-17}$ & $\mathrm{R}_{\mathrm{t}-18}$ & $\mathrm{R}_{\mathrm{t}-19}$ & $R_{t-20}$ & $\mathrm{R}_{\mathrm{t}-21}$ & $R_{t-22}$ & $R_{t-23}$ & $\mathrm{R}_{\mathrm{t}-24}$ & $\mathrm{R}_{\mathrm{t}-25}$ \\
\hline Coef. & -0.29 & 0.10 & 0.08 & 0.19 & -0.27 & 0.17 & 0.09 & 0.08 & -0.22 & -0.11 & -0.18 & -0.27 \\
\hline Reg. t-stat & -3.91 & 1.44 & 1.22 & 2.62 & -3.73 & 2.46 & 1.41 & 1.33 & -3.02 & -1.66 & -2.51 & -3.33 \\
\hline Diff. t-stat & 1.94 & -0.73 & -1.03 & 0.57 & 1.73 & 0.35 & -0.76 & -0.98 & 1.07 & -0.61 & 0.48 & 1.51 \\
\hline $\mathrm{N}$ & 403,507 & 400,578 & 398,413 & 395,794 & 394,029 & 391,120 & 389,669 & 387,184 & 385,720 & 382,822 & 381,436 & 378,767 \\
\hline \multirow[t]{2}{*}{ Adjusted $\mathrm{R}^{2}$} & $22.79 \%$ & $22.67 \%$ & $22.54 \%$ & $22.38 \%$ & $22.17 \%$ & $21.97 \%$ & $21.80 \%$ & $21.65 \%$ & $21.49 \%$ & $21.31 \%$ & $21.17 \%$ & $20.99 \%$ \\
\hline & $R_{t-26}$ & $R_{t-27}$ & $R_{t-28}$ & $\mathrm{R}_{\mathrm{t}-29}$ & $R_{t-30}$ & $R_{t-31}$ & $R_{t-32}$ & $R_{t-33}$ & $R_{t-34}$ & $R_{t-35}$ & $R_{t-36}$ & $\mathbf{R}_{\mathrm{t}-37}$ \\
\hline Coef. & 0.08 & 0.23 & 0.12 & 0.13 & 0.09 & 0.14 & 0.15 & 0.01 & -0.01 & -0.19 & -0.25 & -0.43 \\
\hline Reg. t-stat & 1.20 & 3.10 & 1.74 & 1.86 & 1.39 & 1.96 & 2.03 & 0.33 & -0.14 & -2.55 & -3.12 & -4.30 \\
\hline Diff. t-stat & -1.06 & 1.12 & -0.29 & -0.25 & -0.88 & -0.01 & 0.01 & -4.26 & -2.07 & 0.55 & 1.33 & 2.85 \\
\hline $\mathrm{N}$ & 380,512 & 377,904 & 375,120 & 373,385 & 371,617 & 369,063 & 366,879 & 365,162 & 363,731 & 361,676 & 359,114 & 357,322 \\
\hline Adjusted $\mathrm{R}^{2}$ & $20.36 \%$ & $20.16 \%$ & $20.05 \%$ & $19.91 \%$ & $19.78 \%$ & $19.66 \%$ & $19.48 \%$ & $19.29 \%$ & $19.10 \%$ & $18.98 \%$ & $18.81 \%$ & $18.65 \%$ \\
\hline
\end{tabular}




\begin{tabular}{|c|c|c|c|c|c|c|c|c|c|c|c|c|}
\hline & $\mathrm{R}_{\mathrm{t}-38}$ & $R_{t-39}$ & $\mathrm{R}_{\mathrm{t}-40}$ & $\mathrm{R}_{\mathrm{t}-41}$ & $\mathrm{R}_{\mathrm{t}-42}$ & $\mathrm{R}_{\mathrm{t}-43}$ & $\mathrm{R}_{\mathrm{t}-44}$ & $\mathrm{R}_{\mathrm{t}-45}$ & $\mathrm{R}_{\mathrm{t}-46}$ & $\mathrm{R}_{\mathrm{t}-47}$ & $\mathrm{R}_{\mathrm{t}-48}$ & $\mathrm{R}_{\mathrm{t}-49}$ \\
\hline Coef. & -0.19 & -0.19 & 0.12 & 0.10 & 0.13 & -0.18 & -0.16 & -0.27 & 0.13 & 0.15 & 0.13 & -0.17 \\
\hline Reg. t-stat & -2.95 & -2.95 & 1.68 & 1.64 & 1.92 & -2.52 & -2.12 & -3.54 & 1.92 & 2.06 & 1.87 & -2.49 \\
\hline Diff. t-stat & 0.73 & 0.74 & -0.42 & -0.63 & -0.22 & 0.49 & 0.17 & 1.61 & -0.17 & 0.02 & -0.24 & 0.41 \\
\hline $\mathrm{N}$ & 348,012 & 344,491 & 341,421 & 338,142 & 334,007 & 331,006 & 328,159 & 324,349 & 320,266 & 317,078 & 313,458 & 310,568 \\
\hline \multirow[t]{2}{*}{ Adjusted $\mathrm{R}^{2}$} & $18.20 \%$ & $18.02 \%$ & $17.91 \%$ & $17.78 \%$ & $17.67 \%$ & $17.52 \%$ & $17.40 \%$ & $17.28 \%$ & $17.11 \%$ & $17.00 \%$ & $16.83 \%$ & $16.72 \%$ \\
\hline & $\mathrm{R}_{\mathrm{t}-50}$ & $\mathrm{R}_{\mathrm{t}-51}$ & $\mathrm{R}_{\mathrm{t}-52}$ & $R_{t-53}$ & $\mathrm{R}_{\mathrm{t}-54}$ & $\mathrm{R}_{\mathrm{t}-55}$ & $\mathrm{R}_{\mathrm{t}-56}$ & $\mathrm{R}_{\mathrm{t}-57}$ & $\mathrm{R}_{\mathrm{t}-58}$ & $\mathrm{R}_{\mathrm{t}-59}$ & $\mathrm{R}_{\mathrm{t}-60}$ & $\mathbf{R}_{\mathrm{t}-61}$ \\
\hline Coef. & 0.10 & 0.09 & 0.18 & 0.07 & 0.15 & 0.08 & -0.12 & -0.19 & -0.13 & 0.19 & 0.14 & -0.28 \\
\hline Reg. t-stat & 1.56 & 1.34 & 2.53 & 1.01 & 2.10 & 1.11 & -1.72 & -2.77 & -1.80 & 2.92 & 1.92 & -3.74 \\
\hline Diff. t-stat & -0.68 & -0.85 & 0.53 & -1.08 & 0.09 & -1.01 & -0.35 & 0.64 & -0.27 & 0.69 & -0.08 & 1.80 \\
\hline $\mathrm{N}$ & 308,801 & 304,975 & 302,097 & 298,173 & 295,673 & 292,895 & 290,368 & 287,747 & 284,090 & 280,348 & 277,562 & 274,148 \\
\hline \multirow[t]{2}{*}{ Adjusted $\mathrm{R}^{2}$} & $16.55 \%$ & $16.45 \%$ & $16.30 \%$ & $16.19 \%$ & $16.03 \%$ & $15.91 \%$ & $15.76 \%$ & $15.66 \%$ & $15.55 \%$ & $15.41 \%$ & $15.29 \%$ & $15.21 \%$ \\
\hline & $\mathrm{R}_{\mathrm{t}-62}$ & $\mathrm{R}_{\mathrm{t}-63}$ & $\mathrm{R}_{\mathrm{t}-64}$ & $\mathrm{R}_{\mathrm{t}-65}$ & $\mathrm{R}_{\mathrm{t}-66}$ & $\mathrm{R}_{\mathrm{t}-67}$ & $\mathrm{R}_{\mathrm{t}-68}$ & $\mathrm{R}_{\mathrm{t}-69}$ & $\mathrm{R}_{\mathrm{t}-70}$ & $\mathrm{R}_{\mathrm{t}-71}$ & $\mathrm{R}_{\mathrm{t}-72}$ & $\mathrm{R}_{\mathrm{t}-73}$ \\
\hline Coef. & 0.08 & 0.07 & 0.12 & 0.09 & 0.09 & 0.06 & 0.07 & -0.15 & -0.10 & 0.08 & 0.10 & 0.06 \\
\hline Reg. t-stat & 1.26 & 0.99 & 1.71 & 1.33 & 1.40 & 0.91 & 1.07 & -2.07 & -1.63 & 1.28 & 1.50 & 0.87 \\
\hline Diff. t-stat & -1.07 & -1.21 & -0.4 & -0.86 & -0.85 & -1.16 & -1.09 & 0.08 & -0.67 & -0.99 & -0.73 & -1.15 \\
\hline $\mathrm{N}$ & 270,880 & 268,244 & 264,796 & 261,989 & 258,582 & 255,066 & 251,679 & 248,800 & 245,620 & 243,126 & 240,018 & 237,237 \\
\hline Adjusted $\mathrm{R}^{2}$ & $14.76 \%$ & $14.62 \%$ & $14.49 \%$ & $14.35 \%$ & $14.25 \%$ & $14.16 \%$ & $14.03 \%$ & $13.95 \%$ & $13.87 \%$ & $13.75 \%$ & $13.67 \%$ & $13.58 \%$ \\
\hline
\end{tabular}

Panel B: Base model with flows

\begin{tabular}{|c|c|c|c|c|c|c|c|c|c|c|c|c|}
\hline & $\mathrm{R}_{\mathrm{t}-2}$ & $R_{t-3}$ & $\mathrm{R}_{\mathrm{t}-4}$ & $\mathrm{R}_{\mathrm{t}-5}$ & $\mathrm{R}_{\mathrm{t}-6}$ & $\mathrm{R}_{\mathrm{t}-7}$ & $\mathrm{R}_{\mathrm{t}-8}$ & $\mathrm{R}_{\mathrm{t}-9}$ & $\mathrm{R}_{\mathrm{t}-10}$ & $\mathrm{R}_{\mathrm{t}-11}$ & $\mathrm{R}_{\mathrm{t}-12}$ & $\mathbf{R}_{\mathrm{t}-13}$ \\
\hline Coef. & 0.11 & 0.09 & 0.14 & 0.09 & -0.22 & 0.23 & 0.09 & 0.21 & 0.08 & 0.10 & -0.20 & -0.28 \\
\hline Reg. t-stat & 1.53 & 1.23 & 2.08 & 1.29 & -3.04 & 3.06 & 1.30 & 2.92 & 1.00 & 1.52 & -2.67 & -3.60 \\
\hline Diff. t-stat & -0.47 & -0.73 & -0.05 & -0.77 & -1.06 & -1.15 & -0.78 & -0.92 & -0.8 & -0.66 & -0.75 & -1.76 \\
\hline $\mathrm{N}$ & 425,781 & 423,464 & 421,101 & 418,218 & 415,466 & 413,988 & 411,269 & 408,523 & 405,527 & 402,662 & 400,511 & 397,586 \\
\hline \multirow[t]{2}{*}{ Adjusted $\mathrm{R}^{2}$} & $25.55 \%$ & $25.32 \%$ & $25.14 \%$ & $24.93 \%$ & $24.80 \%$ & $24.64 \%$ & $24.43 \%$ & $24.28 \%$ & $24.11 \%$ & $23.91 \%$ & $23.77 \%$ & $23.61 \%$ \\
\hline & $\mathrm{R}_{\mathrm{t}-14}$ & $\mathrm{R}_{\mathrm{t}-15}$ & $\mathrm{R}_{\mathrm{t}-16}$ & $\mathrm{R}_{\mathrm{t}-17}$ & $\mathrm{R}_{\mathrm{t}-18}$ & $\mathrm{R}_{\mathrm{t}-19}$ & $\mathrm{R}_{\mathrm{t}-20}$ & $\mathrm{R}_{\mathrm{t}-21}$ & $\mathrm{R}_{\mathrm{t}-22}$ & $\mathrm{R}_{\mathrm{t}-23}$ & $\mathrm{R}_{\mathrm{t}-24}$ & $\mathrm{R}_{\mathrm{t}-25}$ \\
\hline Coef. & -0.21 & 0.08 & 0.10 & 0.23 & -0.23 & 0.14 & 0.11 & 0.11 & -0.18 & -0.09 & -0.18 & -0.27 \\
\hline Reg. t-stat & -2.94 & 1.02 & 1.52 & 3.13 & -3.17 & 2.09 & 1.53 & 1.54 & -2.43 & -1.33 & -2.43 & -3.59 \\
\hline Diff. t-stat & -0.93 & -0.81 & -0.66 & -1.18 & -1.19 & -0.05 & -0.47 & -0.47 & -0.49 & -0.79 & -0.49 & -1.68 \\
\hline $\mathrm{N}$ & 403,507 & 400,578 & 398,413 & 395,794 & 394,029 & 391,120 & 389,669 & 387,184 & 385,720 & 382,822 & 381,436 & 378,767 \\
\hline \multirow[t]{2}{*}{ Adjusted $\mathrm{R}^{2}$} & $22.98 \%$ & $22.83 \%$ & $22.64 \%$ & $22.50 \%$ & $22.36 \%$ & $22.18 \%$ & $22.03 \%$ & $21.81 \%$ & $21.67 \%$ & $21.47 \%$ & $21.30 \%$ & $21.13 \%$ \\
\hline & $\mathrm{R}_{\mathrm{t}-26}$ & $\mathrm{R}_{\mathrm{t}-27}$ & $\mathrm{R}_{\mathrm{t}-28}$ & $\mathrm{R}_{\mathrm{t}-29}$ & $\mathrm{R}_{\mathrm{t}-30}$ & $\mathrm{R}_{\mathrm{t}-31}$ & $R_{t-32}$ & $R_{t-33}$ & $\mathrm{R}_{\mathrm{t}-34}$ & $\mathrm{R}_{\mathrm{t}-35}$ & $\mathrm{R}_{\mathrm{t}-36}$ & $\mathbf{R}_{\mathrm{t}-37}$ \\
\hline Coef. & 0.09 & 0.19 & 0.12 & 0.15 & 0.08 & 0.12 & 0.15 & 0.01 & -0.01 & -0.21 & -0.21 & -0.38 \\
\hline Reg. t-stat & 1.37 & 2.53 & 1.84 & 2.14 & 1.03 & 1.85 & 2.24 & 0.21 & -0.34 & -2.94 & -3.00 & -3.78 \\
\hline Diff. t-stat & -0.82 & -0.62 & -0.36 & -0.09 & -0.82 & -0.36 & -0.1 & -2.75 & -4.51 & -0.93 & -0.95 & 2.35 \\
\hline $\mathrm{N}$ & 380,512 & 377,904 & 375,120 & 373,385 & 371,617 & 369,063 & 366,879 & 365,162 & 363,731 & 361,676 & 359,114 & 357,322 \\
\hline Adjusted $\mathrm{R}^{2}$ & $23.29 \%$ & $23.09 \%$ & $22.90 \%$ & $22.71 \%$ & $22.52 \%$ & $22.32 \%$ & $22.19 \%$ & $21.97 \%$ & $21.78 \%$ & $21.58 \%$ & $21.40 \%$ & 0.21 \\
\hline
\end{tabular}




\begin{tabular}{|c|c|c|c|c|c|c|c|c|c|c|c|c|}
\hline & $\mathrm{R}_{\mathrm{t}-38}$ & $R_{t-39}$ & $\mathrm{R}_{\mathrm{t}-40}$ & $\mathrm{R}_{\mathrm{t}-41}$ & $\mathrm{R}_{\mathrm{t}-42}$ & $\mathrm{R}_{\mathrm{t}-43}$ & $\mathrm{R}_{\mathrm{t}-44}$ & $\mathrm{R}_{\mathrm{t}-45}$ & $\mathrm{R}_{\mathrm{t}-46}$ & $\mathrm{R}_{\mathrm{t}-47}$ & $\mathrm{R}_{\mathrm{t}-48}$ & $\mathrm{R}_{\mathrm{t}-49}$ \\
\hline Coef. & -0.22 & -0.16 & 0.11 & 0.09 & 0.14 & -0.20 & -0.18 & -0.23 & 0.11 & 0.18 & 0.11 & -0.19 \\
\hline Reg. t-stat & -3.04 & -2.42 & 1.61 & 1.39 & 2.12 & -2.73 & -2.45 & -3.58 & 1.63 & 2.45 & 1.70 & -2.54 \\
\hline Diff. t-stat & -1.06 & -0.25 & -0.49 & -0.83 & -0.05 & -0.77 & -0.5 & -1.34 & -0.5 & -0.5 & -0.52 & -0.62 \\
\hline $\mathrm{N}$ & 348,012 & 344,491 & 341,421 & 338,142 & 334,007 & 331,006 & 328,159 & 324,349 & 320,266 & 317,078 & 313,458 & 310,568 \\
\hline \multirow[t]{2}{*}{ Adjusted $\mathrm{R}^{2}$} & $21.55 \%$ & $21.42 \%$ & $21.31 \%$ & $21.19 \%$ & $21.04 \%$ & $20.87 \%$ & $20.71 \%$ & $20.51 \%$ & $20.38 \%$ & $20.25 \%$ & $20.09 \%$ & $19.96 \%$ \\
\hline & $\mathrm{R}_{\mathrm{t}-50}$ & $\mathrm{R}_{\mathrm{t}-51}$ & $\mathrm{R}_{\mathrm{t}-52}$ & $\mathrm{R}_{\mathrm{t}-53}$ & $\mathrm{R}_{\mathrm{t}-54}$ & $\mathrm{R}_{\mathrm{t}-55}$ & $\mathrm{R}_{\mathrm{t}-56}$ & $\mathrm{R}_{\mathrm{t}-57}$ & $\mathrm{R}_{\mathrm{t}-58}$ & $\mathrm{R}_{\mathrm{t}-59}$ & $\mathrm{R}_{\mathrm{t}-60}$ & $\mathbf{R}_{\mathrm{t}-61}$ \\
\hline Coef. & 0.13 & 0.11 & 0.19 & 0.08 & 0.19 & 0.09 & -0.13 & -0.20 & -0.13 & 0.18 & 0.12 & -0.28 \\
\hline Reg. t-stat & 1.98 & 1.72 & 2.59 & 1.04 & 2.67 & 1.41 & -2.02 & -2.90 & -2.03 & 2.53 & 1.86 & -3.77 \\
\hline Diff. t-stat & -0.21 & -0.53 & -0.63 & -0.83 & -0.65 & -0.84 & -0.21 & -0.82 & -0.21 & -0.51 & -0.37 & -1.84 \\
\hline $\mathrm{N}$ & 308,801 & 304,975 & 302,097 & 298,173 & 295,673 & 292,895 & 290,368 & 287,747 & 284,090 & 280,348 & 277,562 & 274,148 \\
\hline \multirow[t]{2}{*}{ Adjusted $\mathrm{R}^{2}$} & $21.39 \%$ & $21.27 \%$ & $21.12 \%$ & $20.94 \%$ & $20.77 \%$ & $20.62 \%$ & $20.41 \%$ & $20.27 \%$ & $20.13 \%$ & $19.97 \%$ & $19.79 \%$ & $19.67 \%$ \\
\hline & $\mathrm{R}_{\mathrm{t}-62}$ & $\mathrm{R}_{\mathrm{t}-63}$ & $\mathrm{R}_{\mathrm{t}-64}$ & $\mathrm{R}_{\mathrm{t}-65}$ & $\mathrm{R}_{\mathrm{t}-66}$ & $\mathrm{R}_{\mathrm{t}-67}$ & $\mathrm{R}_{\mathrm{t}-68}$ & $\mathrm{R}_{\mathrm{t}-69}$ & $\mathrm{R}_{\mathrm{t}-70}$ & $\mathrm{R}_{\mathrm{t}-71}$ & $\mathrm{R}_{\mathrm{t}-72}$ & $\mathrm{R}_{\mathrm{t}-73}$ \\
\hline Coef. & 0.08 & 0.07 & 0.11 & 0.09 & 0.10 & 0.08 & 0.08 & -0.16 & -0.10 & 0.06 & 0.10 & 0.07 \\
\hline Reg. t-stat & 1.05 & 0.94 & 1.79 & 1.21 & 1.44 & 1.16 & 1.17 & -2.28 & -1.43 & 0.91 & 1.45 & 0.96 \\
\hline Diff. t-stat & -0.78 & -1.04 & -0.54 & -0.74 & -0.66 & -0.85 & -0.83 & -0.22 & 0.67 & -1.3 & -0.64 & -1.01 \\
\hline $\mathrm{N}$ & 270,880 & 268,244 & 264,796 & 261,989 & 258,582 & 255,066 & 251,679 & 248,800 & 245,620 & 243,126 & 240,018 & 237,237 \\
\hline Adjusted $\mathrm{R}^{2}$ & $19.70 \%$ & $19.59 \%$ & $19.42 \%$ & $19.28 \%$ & $19.09 \%$ & $18.98 \%$ & $18.83 \%$ & $18.67 \%$ & $18.51 \%$ & $18.38 \%$ & $18.27 \%$ & $18.11 \%$ \\
\hline
\end{tabular}

Panel C: Simultaneous Estimation Model (N=237,237, Adj. $\left.\mathrm{R}^{2}=27.90\right)$

\begin{tabular}{|c|c|c|c|c|c|c|c|c|c|c|c|c|}
\hline & $\mathrm{R}_{\mathrm{t}-2}$ & $\mathrm{R}_{\mathrm{t}-3}$ & $\mathrm{R}_{\mathrm{t}-4}$ & $\mathrm{R}_{\mathrm{t}-5}$ & $\mathrm{R}_{\mathrm{t}-6}$ & $\mathrm{R}_{\mathrm{t}-7}$ & $\mathrm{R}_{\mathrm{t}-8}$ & $R_{t-9}$ & $\mathrm{R}_{\mathrm{t}-10}$ & $\mathrm{R}_{\mathrm{t}-11}$ & $\mathrm{R}_{\mathrm{t}-12}$ & $\mathbf{R}_{\mathrm{t}-13}$ \\
\hline Coef. & 0.12 & 0.11 & 0.15 & -0.13 & -0.40 & -0.33 & 0.09 & 0.14 & -0.05 & 0.10 & -0.31 & -0.42 \\
\hline Reg. t-stat & 1.70 & 1.51 & 2.15 & -1.99 & -4.22 & -4.18 & 1.28 & 2.05 & -0.73 & 1.39 & -3.88 & -4.38 \\
\hline \multirow[t]{2}{*}{ Diff. t-stat } & -0.34 & -0.43 & 0.19 & -0.16 & 2.75 & 2.40 & -0.71 & -0.05 & -1.26 & -0.62 & 2.10 & 2.91 \\
\hline & $\mathrm{R}_{\mathrm{t}-14}$ & $\mathrm{R}_{\mathrm{t}-15}$ & $\mathrm{R}_{\mathrm{t}-16}$ & $\mathrm{R}_{\mathrm{t}-17}$ & $\mathrm{R}_{\mathrm{t}-18}$ & $\mathrm{R}_{\mathrm{t}-19}$ & $\mathrm{R}_{\mathrm{t}-20}$ & $\mathrm{R}_{\mathrm{t}-21}$ & $\mathrm{R}_{\mathrm{t}-22}$ & $\mathrm{R}_{\mathrm{t}-23}$ & $\mathrm{R}_{\mathrm{t}-24}$ & $\mathrm{R}_{\mathrm{t}-25}$ \\
\hline Coef. & 0.20 & 0.07 & 0.07 & -0.13 & -0.15 & -0.17 & 0.10 & 0.12 & 0.13 & 0.05 & -0.14 & -0.21 \\
\hline Reg. t-stat & 2.88 & 0.99 & 1.00 & -1.98 & -2.08 & -2.16 & 1.41 & 1.73 & 1.98 & 0.72 & -2.02 & -2.89 \\
\hline \multirow[t]{2}{*}{ Diff. t-stat } & 0.86 & -1.13 & -1.13 & -0.21 & 0.06 & 0.31 & -0.60 & -0.33 & -0.18 & -1.43 & -0.09 & 0.92 \\
\hline & $\mathrm{R}_{\mathrm{t}-26}$ & $\mathrm{R}_{\mathrm{t}-27}$ & $\mathrm{R}_{\mathrm{t}-28}$ & $\mathrm{R}_{\mathrm{t}-29}$ & $\mathrm{R}_{\mathrm{t}-30}$ & $\mathrm{R}_{\mathrm{t}-31}$ & $\mathrm{R}_{\mathrm{t}-32}$ & $\mathrm{R}_{\mathrm{t}-33}$ & $\mathrm{R}_{\mathrm{t}-34}$ & $\mathrm{R}_{\mathrm{t}-35}$ & $\mathrm{R}_{\mathrm{t}-36}$ & $\mathbf{R}_{\mathrm{t}-37}$ \\
\hline Coef. & -0.16 & 0.18 & 0.14 & -0.15 & -0.11 & 0.13 & 0.11 & -0.01 & -0.01 & 0.17 & -0.18 & -0.29 \\
\hline Reg. t-stat & -2.15 & 2.57 & 2.03 & -2.13 & -1.50 & 1.86 & 1.50 & -0.08 & -0.10 & 2.20 & -2.54 & -3.51 \\
\hline \multirow[t]{2}{*}{ Diff. t-stat } & 0.25 & 0.58 & -0.04 & 0.18 & -0.44 & -0.23 & -0.47 & -0.90 & -1.02 & 0.33 & 0.54 & 1.78 \\
\hline & $\mathrm{R}_{\mathrm{t}-38}$ & $\mathrm{R}_{\mathrm{t}-39}$ & $\mathrm{R}_{\mathrm{t}-40}$ & $\mathrm{R}_{\mathrm{t}-41}$ & $\mathrm{R}_{\mathrm{t}-42}$ & $\mathrm{R}_{\mathrm{t}-43}$ & $\mathrm{R}_{\mathrm{t}-44}$ & $\mathrm{R}_{\mathrm{t}-45}$ & $\mathrm{R}_{\mathrm{t}-46}$ & $\mathrm{R}_{\mathrm{t}-47}$ & $\mathrm{R}_{\mathrm{t}-48}$ & $\mathrm{R}_{\mathrm{t}-49}$ \\
\hline Coef. & 0.21 & 0.15 & 0.06 & 0.12 & 0.17 & -0.18 & -0.13 & 0.18 & 0.14 & -0.12 & -0.12 & -0.10 \\
\hline Reg. t-stat & 2.99 & 2.12 & 0.84 & 1.64 & 2.33 & -2.62 & -1.87 & 2.85 & 2.04 & -1.81 & -1.60 & -1.33 \\
\hline Diff. t-stat & 1.00 & 0.09 & -1.01 & -0.34 & 0.38 & 0.59 & -0.23 & 0.65 & -0.01 & -0.30 & -0.35 & -0.62 \\
\hline
\end{tabular}




\begin{tabular}{|c|c|c|c|c|c|c|c|c|c|c|c|c|}
\hline & $\mathrm{R}_{\mathrm{t}-50}$ & $\mathrm{R}_{\mathrm{t}-51}$ & $\mathrm{R}_{\mathrm{t}-52}$ & $\mathrm{R}_{\mathrm{t}-53}$ & $\mathrm{R}_{\mathrm{t}-54}$ & $\mathrm{R}_{\mathrm{t}-55}$ & $\mathrm{R}_{\mathrm{t}-56}$ & $\mathrm{R}_{\mathrm{t}-57}$ & $\mathrm{R}_{\mathrm{t}-58}$ & $\mathrm{R}_{\mathrm{t}-59}$ & $\mathrm{R}_{\mathrm{t}-60}$ & $\mathbf{R}_{\mathrm{t}-61}$ \\
\hline Coef. & -0.09 & -0.12 & 0.18 & 0.07 & 0.24 & 0.10 & 0.20 & 0.20 & -0.13 & 0.21 & -0.11 & -0.30 \\
\hline Reg. t-stat & -1.16 & -1.82 & 2.43 & 0.92 & 3.15 & 1.39 & 2.85 & 2.85 & -1.93 & 2.99 & -1.50 & -3.66 \\
\hline \multirow[t]{2}{*}{ Diff. t-stat } & -0.72 & -0.30 & 0.49 & -1.07 & 1.33 & -0.63 & 0.83 & 0.79 & -0.23 & 0.98 & -0.45 & 1.95 \\
\hline & $\mathrm{R}_{\mathrm{t}-62}$ & $\mathrm{R}_{\mathrm{t}-63}$ & $\mathrm{R}_{\mathrm{t}-64}$ & $\mathrm{R}_{\mathrm{t}-65}$ & $\mathrm{R}_{\mathrm{t}-66}$ & $\mathrm{R}_{\mathrm{t}-67}$ & $\mathrm{R}_{\mathrm{t}-68}$ & $\mathrm{R}_{\mathrm{t}-69}$ & $\mathrm{R}_{\mathrm{t}-70}$ & $\mathrm{R}_{\mathrm{t}-71}$ & $\mathrm{R}_{\mathrm{t}-72}$ & $\mathrm{R}_{\mathrm{t}-73}$ \\
\hline Coef. & 0.09 & 0.06 & 0.12 & 0.08 & 0.11 & 0.07 & 0.07 & -0.12 & -0.10 & 0.06 & 0.10 & 0.06 \\
\hline Reg. t-stat & 1.29 & 0.85 & 1.60 & 1.10 & 1.53 & 1.10 & 1.08 & -1.67 & -1.48 & 0.90 & 1.43 & 0.79 \\
\hline Diff. t-stat & -0.66 & -1.02 & -0.37 & -0.84 & -0.39 & -0.97 & -0.96 & -0.34 & -0.59 & -1.08 & -0.59 & -1.23 \\
\hline
\end{tabular}

Panel D: Base model with flows

\begin{tabular}{lcc} 
Model & $(1)$ & $(2)$ \\
\hline $\mathrm{R}_{t}$ & & $0.45^{* * *}$ \\
& & $(4.17)$ \\
$\mathrm{R}_{t-1}$ & $0.39^{* * *}$ & $0.34^{* * *}$ \\
& $(4.43)$ & $(3.54)$ \\
$\mathrm{R}_{t-1, t-12}$ & $0.06^{* *}$ & $0.06^{* *}$ \\
& $(2.16)$ & $(2.23)$ \\
$\mathrm{R}_{t-13}$ & $-0.30^{* * *}$ & $-0.32^{* * *}$ \\
& $(-3.16)$ & $(-3.71)$ \\
$\mathrm{R}_{t-15, t-36}$ & $0.01^{* *}$ & $0.01^{* *}$ \\
& $(2.27)$ & $(2.37)$ \\
$\mathrm{R}_{t-37}$ & $-0.37^{* * *}$ & $-0.40^{* * *}$ \\
& $(-4.64)$ & $(-3.78)$ \\
$\mathrm{R}_{t-39, t-60}$ & 0.01 & $0.02^{* *}$ \\
& $(1.85)$ & $(2.37)$ \\
$\mathrm{R}_{t-61}$ & $-0.26^{* * *}$ & $-0.29^{* * *}$ \\
& $(-3.27)$ & $(-4.01)$ \\
$\mathrm{N}$ & 237,237 & 237,237 \\
Adjusted $\mathrm{R}^{2}$ & $36.21 \%$ & $38.17 \%$ \\
\hline
\end{tabular}

Coefficients are reported with difference t-statistics (as defined in Table 1 of the main paper) reported in brackets. Coefficients significant at the $1 \%$ and $5 \%$ levels are marked with $* * *$ and ${ }^{* *}$ respectively. 
Panel E: Robustness Tests and Extensions

\begin{tabular}{|c|c|c|c|c|c|c|c|}
\hline Model & Dep. Var. & Clustered S.E. & Fixed Effects & Controls & $\mathrm{R}_{\mathrm{t}-13}$ & $\mathrm{R}_{\mathrm{t}-37}$ & $\mathrm{R}_{\mathrm{t}-61}$ \\
\hline (1) & $\Delta$ Market Share & Fund, Date & No & No & $\begin{array}{c}-0.33 \\
(-4.11)\end{array}$ & $\begin{array}{c}-0.43 \\
(-2.85)\end{array}$ & $\begin{array}{c}-0.28 \\
(-3.74)\end{array}$ \\
\hline (2) & $\Delta$ Market Share & Fund, Time, Family & No & No & $\begin{array}{l}-0.33 \\
(-3.62)\end{array}$ & $\begin{array}{l}-0.43 \\
(-4.44)\end{array}$ & $\begin{array}{l}-0.28 \\
(-3.45)\end{array}$ \\
\hline (3) & $\Delta$ Market Share & Fund, Date & No & Yes & $\begin{array}{l}-0.34 \\
(-3.79)\end{array}$ & $\begin{array}{l}-0.36 \\
(-4.31)\end{array}$ & $\begin{array}{l}-0.23 \\
(-2.96)\end{array}$ \\
\hline (4) & $\Delta$ Market Share & Fund, Date & Fund Objective & No & $\begin{array}{c}-0.26 \\
(-3.72)\end{array}$ & $\begin{array}{c}-0.35 \\
(-3.44)\end{array}$ & $\begin{array}{l}-0.30 \\
(-3.20)\end{array}$ \\
\hline (5) & $\Delta$ Market Share & Fund, Date & Fund Objective & Yes & $\begin{array}{c}-0.33 \\
(-3.58)\end{array}$ & $\begin{array}{l}-0.34 \\
(-4.11)\end{array}$ & $\begin{array}{l}-0.35 \\
(-4.63)\end{array}$ \\
\hline (6) & N-SAR Net Sales & Fund, Date & No & No & $\begin{array}{c}-0.34 \\
(-3.61) \\
\end{array}$ & $\begin{array}{c}-0.39 \\
(-3.68) \\
\end{array}$ & $\begin{array}{c}-0.41 \\
(-3.75) \\
\end{array}$ \\
\hline
\end{tabular}

Interpretation: This table demonstrates that investors allocate disproportionate capital to funds with negative returns 13,37 , and 61 months prior. These returns coincide with the end of commonly reported holding periods for mutual funds, suggesting that investors are unable to differentiate between improvements in HPRs which result from high recent returns $\left(\right.$ Return $\left._{t-1}\right)$ relative to improvements related to negative returns dropping from the horizon of the HPR calculation. 


\section{Table II}

\section{Advertising Expenditure Dataset Summary Statistics}

This table summarizes investment company advertising expenditures in print media in the U.S. by year (thousand USD). Expenditures are segmented between magazine and newspaper advertisements. Magazine advertisement expenditures are subsequently segmented by whether the advertisement promotes mutual funds or promotes another product or service provided by the mutual fund company. Expenditures focused on mutual fund advertising are subsequently segmented by: 1) expenditures that promote a specific fund relative to broad family based promotion, 2) expenditures which promote holding period returns (HPR) by horizon, 3) expenditures which promote rankings provided by Morningstar or another analyst by horizon and 4) analyst rankings not by horizon. Greater detail regarding the establishment of the partitions is provided in the Appendix.

\begin{tabular}{lcccccccc}
\hline \hline & 2005 & 2006 & 2007 & 2008 & 2009 & 2010 & Total & \% of Total \\
\hline & & \multicolumn{7}{c}{ All Advertising } \\
Newspaper & 61,427 & 58,794 & 89,764 & 96,690 & 103,630 & 126,881 & 537,186 & 34 \\
Magazine & 148,643 & 169,341 & 184,043 & 213,006 & 147,315 & 182,969 & $1,045,317$ & 66 \\
Total & 210,070 & 228,135 & 273,807 & 309,696 & 250,945 & 309,850 & $1,582,503$
\end{tabular}

$\begin{array}{lcccccccc}\text { Not Mutual Fund Focused } & 84,061 & 96,872 & 110,181 & 149,840 & 123,985 & 147,823 & 712,762 & 68 \\ \text { Mutual Fund Focused } & 64,582 & 72,469 & 73,862 & 63,166 & 23,330 & 35,146 & 332,555 & 32\end{array}$

Mutual Fund Focused Magazine Advertising

Fund Specific

Family

\begin{tabular}{lllll}
49,869 & 52,658 & 54,202 & 39,008 & 15,5 \\
14,713 & 19,811 & 19,660 & 24,158 & 7,813 \\
\multicolumn{5}{c}{ Fund Specific Magazine Advertising } \\
28,535 & 23,605 & 20,857 & 13,666
\end{tabular}

Advertise HPR by Horizon

Advertise Rank by Horizon

6,363

23,605

20,857

13,666

1,615

3,818

2,144

5,201

22,321

12,632

9,234

9,770

4,098

6,884

8,892

2,524
$18,212 \quad 229,466$

$16,934 \quad 103,089$

69

31

Interpretation: Investment company advertising expenditure promoting mutual funds is cyclical. It is higher during periods of strong market performance. 


\section{Table III}

\section{Determinants of Holding Period Return Advertising Expenditures}

In this table, the dependent variable is the change in spending on fund specific advertising that features holding period return data or analyst rating in year $T$ standardized by fund size. The key independent variables are holding period returns (HPR) calculated using monthly returns over the prior 1,3 , and 5 year horizons (for example, $H P R_{T-1}^{3 Y e a r}$ refers to the 3 year HPR ending in year $T$-1). The models are partitioned by the annual return that drops from the 3 and 5 year HPR horizon (i.e. the 1 year HPR 4 years prior $H P R_{T-4}^{1 \text { Year }}$ and the 1 year HPR 6 years prior $H P R_{T-6}^{1}$ Year . Controls include: the logarithm of: fund age measured from the date of fund inception to the start of the year of $\beta_{n}$ estimation, \# of funds offered by the investment company (family) of the fund and total family TNA. Fund flow is the percentage growth in mutual fund TNA, defined as: $\left(T N A_{i, t}-T N A_{i, t-1} \times\left(1+\operatorname{Return}_{i, t}\right)\right) / T N A_{i, t-1}$ in month $t$ for fund $i$. Fund flow standard deviation is calculated using monthly fund flow over the prior year. Market return is the return to the S\&P 500 index. Expense ratio, front end load, back end load and portfolio turnover are calculated as TNA weighted mean values across all available share classes of each fund. Expense ratio and turnover for each share class is the percentage of TNA charged as operating expenses and the percentage of TNA traded per annum, respectively. Morningstar rating is the number of stars ( 1 to 5 ) assigned to the fund in Morningstar's fund rating system. The regressions include time fixed effects. Standardized coefficient values are reported with t-statistics in parentheses calculated with standard errors clustered by fund. Significance at the $10 \%, 5 \%$ and $1 \%$ levels is indicated by ${ }^{*},{ }^{* *},{ }^{* * *}$, respectively.

Panel A: Advertising Spending that Features HPR Information

\begin{tabular}{|c|c|c|c|c|c|c|c|c|c|c|c|c|}
\hline \multirow{3}{*}{$\begin{array}{l}\text { Dependent Variable } \\
\text { Partition Variable } \\
\text { Model/Partition }\end{array}$} & \multicolumn{12}{|c|}{ 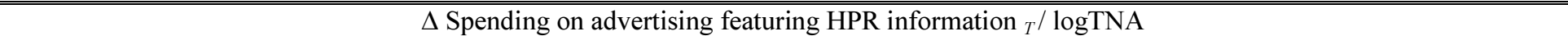 } \\
\hline & \multicolumn{4}{|c|}{ Full Sample } & \multicolumn{4}{|c|}{$H P R_{T-4}^{1 \text { Year }}$} & \multicolumn{4}{|c|}{$H P R_{T-6}^{1 \text { Year }}$} \\
\hline & $(1)$ & $(2)$ & (3) & (4) & Low & Mid & High & L-H & Low & Mid & High & L-H \\
\hline$H P R_{T-1}^{1 \text { Year }}$ & $\begin{array}{l}0.20^{* *} \\
(2.31)\end{array}$ & & & $\begin{array}{l}0.24^{* * *} \\
(3.70)\end{array}$ & $\begin{array}{l}0.24^{* * *} \\
(3.41)\end{array}$ & $\begin{array}{c}0.09 \\
(1.62)\end{array}$ & $\begin{array}{c}0.07 \\
(1.21)\end{array}$ & $\begin{array}{c}0.16^{*} \\
(1.95)\end{array}$ & $\begin{array}{l}0.27^{* * *} \\
(3.93)\end{array}$ & $\begin{array}{c}0.09^{*} \\
(1.91)\end{array}$ & $\begin{array}{l}0.10^{* *} \\
(2.28)\end{array}$ & $\begin{array}{l}0.17^{* *} \\
(2.26)\end{array}$ \\
\hline$H P R_{T-1}^{3 \text { Year }}$ & & $\begin{array}{l}0.25^{* * *} \\
(3.69)\end{array}$ & & $\begin{array}{l}0.21^{* * *} \\
(2.88)\end{array}$ & $\begin{array}{l}0.38^{* * *} \\
(4.85)\end{array}$ & $\begin{array}{l}0.26^{* * *} \\
(4.54)\end{array}$ & $\begin{array}{c}0.06 \\
(1.49)\end{array}$ & $\begin{array}{l}0.32^{* * *} \\
(4.18)\end{array}$ & $\begin{array}{l}0.36^{* * *} \\
(4.06)\end{array}$ & $\begin{array}{l}0.17^{* *} \\
(2.61)\end{array}$ & $\begin{array}{l}0.06^{* *} \\
(2.08)\end{array}$ & $\begin{array}{l}0.30^{* * * *} \\
(3.05)\end{array}$ \\
\hline$H P R_{T-1}^{5 \text { Year }}$ & & & $\begin{array}{l}0.38^{* * *} \\
(4.64)\end{array}$ & $\begin{array}{l}0.25^{* * *} \\
(4.25)\end{array}$ & $\begin{array}{l}0.23^{* * *} \\
(3.06)\end{array}$ & $\begin{array}{c}0.08 \\
(1.74)\end{array}$ & $\begin{array}{l}0.07^{* *} \\
(2.21)\end{array}$ & $\begin{array}{c}0.17^{*} \\
(1.77)\end{array}$ & $\begin{array}{l}0.23^{* * *} \\
(4.15)\end{array}$ & $\begin{array}{l}0.11^{* * * *} \\
(2.68)\end{array}$ & $\begin{array}{c}0.08^{*} \\
(1.85)\end{array}$ & $\begin{array}{l}0.15^{* *} \\
(2.34)\end{array}$ \\
\hline $\log _{\text {Family TNA }}{ }_{T-1}$ & $\begin{array}{l}0.23^{* * *} \\
(3.63)\end{array}$ & $\begin{array}{c}0.10^{*} \\
(1.78)\end{array}$ & $\begin{array}{l}0.21^{* * * *} \\
(2.90)\end{array}$ & $\begin{array}{c}0.09 \\
(1.63)\end{array}$ & $\begin{array}{l}0.14^{* * *} \\
(3.15)\end{array}$ & $\begin{array}{c}0.10 \\
(1.73)\end{array}$ & $\begin{array}{l}0.15^{* * *} \\
(3.24)\end{array}$ & & $\begin{array}{l}0.11^{*} \\
(1.79)\end{array}$ & $\begin{array}{l}0.08^{* *} \\
(2.22)\end{array}$ & $\begin{array}{c}0.12^{*} \\
(1.81)\end{array}$ & \\
\hline Fund Flow ${ }_{T-1}$ & $\begin{array}{l}-0.13 \\
(-1.33)\end{array}$ & $\begin{array}{l}-0.22^{* * *} \\
(-3.17)\end{array}$ & $\begin{array}{l}-0.17^{*} \\
(-1.87)\end{array}$ & $\begin{array}{l}-0.14^{* *} \\
(-2.38)\end{array}$ & $\begin{array}{l}-0.13^{* * *} \\
(-2.20)\end{array}$ & $\begin{array}{l}-0.10^{*} \\
(-1.93)\end{array}$ & $\begin{array}{l}-0.10^{* * *} \\
(-2.32)\end{array}$ & & $\begin{array}{l}-0.10^{*} \\
(-1.95)\end{array}$ & $\begin{array}{l}-0.13^{* *} \\
(-2.43)\end{array}$ & $\begin{array}{l}-0.11^{*} \\
(-1.66)\end{array}$ & \\
\hline Log Fund Age $_{T-1}$ & $\begin{array}{l}-0.10 \\
(-1.34)\end{array}$ & $\begin{array}{l}-0.15^{* * *} \\
(-3.20)\end{array}$ & $\begin{array}{l}-0.14^{* * *} \\
(-3.34)\end{array}$ & $\begin{array}{c}-0.14 \\
(-1.55)\end{array}$ & $\begin{array}{l}-0.22^{* * *} \\
(-3.68)\end{array}$ & $\begin{array}{c}-0.20^{* * * *} \\
(-3.72)\end{array}$ & $\begin{array}{l}-0.14^{* * *} \\
(-2.91)\end{array}$ & & $\begin{array}{l}-0.19^{* * *} \\
(-3.87)\end{array}$ & $\begin{array}{l}-0.19^{* * *} \\
(-2.77)\end{array}$ & $\begin{array}{l}-0.22^{* * *} \\
(-2.74)\end{array}$ & \\
\hline Fund Flow $\operatorname{Std}_{T-1}$ & $\begin{array}{l}0.35^{* * * *} \\
(4.97)\end{array}$ & $\begin{array}{l}0.21^{* * *} \\
(2.53)\end{array}$ & $\begin{array}{l}0.30^{* * * *} \\
(4.63)\end{array}$ & $\begin{array}{l}0.22^{* * * *} \\
(2.72)\end{array}$ & $\begin{array}{l}0.18^{* * * *} \\
(2.89)\end{array}$ & $\begin{array}{l}0.21^{* * *} \\
(2.68)\end{array}$ & $\begin{array}{l}0.25^{* * *} \\
(4.64)\end{array}$ & & $\begin{array}{l}0.20^{* * * *} \\
(2.99)\end{array}$ & $\begin{array}{l}0.23^{* * * *} \\
(3.40)\end{array}$ & $\begin{array}{l}0.24^{* * * *} \\
(2.67)\end{array}$ & \\
\hline Market Return $_{T-1}$ & $\begin{array}{l}0.13^{*} \\
(1.91)\end{array}$ & $\begin{array}{l}0.13^{*} \\
(1.69)\end{array}$ & $\begin{array}{l}0.15^{* * * *} \\
(3.33)\end{array}$ & $\begin{array}{l}0.13^{* * *} \\
(2.39)\end{array}$ & $\begin{array}{l}0.14^{* *} \\
(2.49)\end{array}$ & $\begin{array}{l}0.13^{* *} \\
(2.03)\end{array}$ & $\begin{array}{l}0.10^{* * *} \\
(2.15)\end{array}$ & & $\begin{array}{l}0.13^{* * * *} \\
(2.71)\end{array}$ & $\begin{array}{l}0.16^{* * *} \\
(2.24)\end{array}$ & $\begin{array}{l}0.13^{* * *} \\
(2.54)\end{array}$ & \\
\hline Expense Ratio $_{T-1}$ & $\begin{array}{l}0.17^{* * * *} \\
(3.60)\end{array}$ & $\begin{array}{c}0.14 \\
(1.58)\end{array}$ & $\begin{array}{l}0.19^{* * * *} \\
(3.09)\end{array}$ & $\begin{array}{l}0.16^{* * *} \\
(4.20)\end{array}$ & $\begin{array}{l}0.10^{* * *} \\
(2.91)\end{array}$ & $\begin{array}{c}0.07^{*} \\
(1.90)\end{array}$ & $\begin{array}{l}0.08^{* * *} \\
(2.30)\end{array}$ & & $\begin{array}{l}0.08^{* *} \\
(2.17)\end{array}$ & $\begin{array}{l}0.11^{* *} \\
(2.01)\end{array}$ & $\begin{array}{l}0.10^{*} \\
(1.69)\end{array}$ & \\
\hline Front End Load ${ }_{T-1}$ & $\begin{array}{l}0.22^{* * * *} \\
(2.96)\end{array}$ & $\begin{array}{l}0.18^{* * * *} \\
(3.54)\end{array}$ & $\begin{array}{l}0.32^{* * * *} \\
(3.32)\end{array}$ & $\begin{array}{l}0.18^{* * *} \\
(2.63)\end{array}$ & $\begin{array}{l}0.32^{* * *} \\
(5.02)\end{array}$ & $\begin{array}{l}0.27^{* * *} \\
(3.28)\end{array}$ & $\begin{array}{l}0.24^{* * *} \\
(3.97)\end{array}$ & & $\begin{array}{l}0.31^{* * *} \\
(3.66)\end{array}$ & $\begin{array}{l}0.30^{* * * *} \\
(4.07)\end{array}$ & $\begin{array}{l}0.20^{* *} \\
(2.47)\end{array}$ & \\
\hline Back End Load $_{T-1}$ & $\begin{array}{l}0.05 \\
(1.54)\end{array}$ & $\begin{array}{c}0.04 \\
(1.36)\end{array}$ & $\begin{array}{c}0.04 \\
(0.99)\end{array}$ & $\begin{array}{l}0.03^{*} \\
(1.66)\end{array}$ & $\begin{array}{c}0.03^{*} \\
(1.74)\end{array}$ & $\begin{array}{c}0.03^{*} \\
(1.79)\end{array}$ & $\begin{array}{c}0.03 \\
(1.50)\end{array}$ & & $\begin{array}{c}0.02 \\
(1.38)\end{array}$ & $\begin{array}{c}0.03 \\
(1.32)\end{array}$ & $\begin{array}{c}0.03 \\
(1.48)\end{array}$ & \\
\hline
\end{tabular}




\begin{tabular}{|c|c|c|c|c|c|c|c|c|c|c|}
\hline Turnover $_{T-1}$ & $\begin{array}{c}0.07^{*} \\
(1.84)\end{array}$ & $\begin{array}{c}0.08 \\
(1.57)\end{array}$ & $\begin{array}{c}0.08^{* *} \\
(2.26)\end{array}$ & $\begin{array}{c}0.04 \\
(1.50)\end{array}$ & $\begin{array}{c}0.02 \\
(0.86)\end{array}$ & $\begin{array}{c}0.02 \\
(0.81)\end{array}$ & $\begin{array}{c}0.02 \\
(0.72)\end{array}$ & $\begin{array}{c}0.02 \\
(0.69)\end{array}$ & $\begin{array}{c}0.02 \\
(0.53)\end{array}$ & $\begin{array}{c}0.02 \\
(1.07)\end{array}$ \\
\hline Morningstar Rating $_{T-1}$ & $0.16^{* * *}$ & $0.16^{* * * *}$ & $0.12^{* * *}$ & $0.14^{* * *}$ & $0.09^{* * *}$ & $0.11^{\text {*** }}$ & $0.07^{*}$ & $0.08^{*}$ & 0.06 & 0.07 \\
\hline$\Delta$ Morningstar Rating $_{T-1}$ & $\begin{array}{c}(3.64) \\
0.17^{* *} \\
(2.07)\end{array}$ & $\begin{array}{c}(2.94) \\
0.16^{* *} \\
(2.48)\end{array}$ & $\begin{array}{l}(2.18) \\
0.17^{* * *} \\
(2.82)\end{array}$ & $\begin{array}{c}(2.94) \\
0.17^{* * *} \\
(2.04)\end{array}$ & $\begin{array}{l}(2.53) \\
0.23^{* * *} \\
(2.80)\end{array}$ & $\begin{array}{c}(2.36) \\
0.13^{*} \\
(1.87)\end{array}$ & $\begin{array}{c}(1.69) \\
0.07 \\
(1.55)\end{array}$ & $\begin{array}{l}(1.69) \\
0.25^{* * *} \\
(2.81)\end{array}$ & $\begin{array}{c}(1.42) \\
0.12^{*} \\
(1.73)\end{array}$ & $\begin{array}{c}(1.47) \\
0.05 \\
(1.32)\end{array}$ \\
\hline Adjusted $\mathrm{R}^{2}$ & 0.22 & 0.29 & 0.32 & 0.38 & 0.34 & 0.33 & 0.25 & 0.38 & 0.32 & 0.26 \\
\hline $\mathrm{N}$ & 21,219 & 21,219 & 21,219 & 21,219 & 18,054 & 18,054 & 18,052 & 16,416 & 16,416 & 16,416 \\
\hline
\end{tabular}


Panel B: Advertising Spending that Features Analyst Rating Information

\begin{tabular}{|c|c|c|c|c|c|c|c|c|c|c|c|c|}
\hline \multirow{3}{*}{$\begin{array}{l}\text { Dependent Variable } \\
\text { Partition Variable } \\
\text { Model/Partition }\end{array}$} & \multicolumn{12}{|c|}{$\Delta$ " Spending on advertising featuring analyst rating information ${ }_{T} / \log \mathrm{TNA}$} \\
\hline & \multicolumn{4}{|c|}{ Full Sample } & \multicolumn{4}{|c|}{$H P R_{T-4}^{1}$ Year } & \multicolumn{4}{|c|}{$H P R_{T-6}^{1 \text { Year }}$} \\
\hline & (1) & $(2)$ & $(3)$ & $(4)$ & Low & Mid & High & L-H & Low & Mid & High & L-H \\
\hline \multirow[t]{2}{*}{$H P R_{T-1}^{1 \text { Year }}$} & $0.19^{* *}$ & & & $0.24^{* * *}$ & $0.21^{* * *}$ & $0.10^{* *}$ & 0.07 & 0.14 & $0.23^{* * *}$ & $0.09^{* *}$ & $0.09^{* *}$ & 0.14 \\
\hline & $(2.29)$ & & & (3.97) & (3.61) & $(2.01)$ & $(1.08)$ & (1.63) & $(3.06)$ & $(2.04)$ & (2.27) & $(1.65)$ \\
\hline \multirow[t]{2}{*}{$H P R_{T-1}^{3 \text { Year }}$} & & $0.24^{* * *}$ & & $0.26^{* * *}$ & $0.34^{* * * *}$ & $0.24^{* * * *}$ & 0.08 & $0.27^{* * *}$ & $0.46^{* * *}$ & $0.19^{* *}$ & 0.05 & $0.41^{* * * *}$ \\
\hline & & $(3.88)$ & & $(3.29)$ & $(3.57)$ & $(2.75)$ & $(1.45)$ & $(2.63)$ & $(5.63)$ & $(2.36)$ & $(1.46)$ & $(4.46)$ \\
\hline \multirow[t]{2}{*}{$H P R_{T-1}^{5 \text { Year }}$} & & & $0.35^{* * *}$ & $0.22^{* * *}$ & $0.26^{* * * *}$ & $0.10^{* * * *}$ & $0.06^{*}$ & $0.20^{* * *}$ & $0.26^{* * *}$ & $0.11^{* * *}$ & $0.08^{*}$ & $0.19^{* * *}$ \\
\hline & & & $(5.25)$ & $(3.75)$ & $(4.03)$ & (2.67) & (1.94) & (2.59) & $(3.85)$ & $(2.71)$ & $(1.82)$ & (2.14) \\
\hline \multirow[t]{2}{*}{$\log _{\text {Family TNA }}{ }_{T-1}$} & $0.19^{* * *}$ & $0.13^{* *}$ & $0.18^{* * * *}$ & $0.11^{* *}$ & $0.16^{* * * *}$ & $0.10^{*}$ & $0.14^{* * * *}$ & & $0.10^{*}$ & $0.11^{* * *}$ & $0.12^{* *}$ & \\
\hline & $(2.67)$ & $(2.21)$ & $(2.99)$ & $(2.32)$ & $(3.22)$ & $(1.96)$ & $(3.06)$ & & $(1.75)$ & $(2.86)$ & $(2.03)$ & \\
\hline \multirow{2}{*}{ Fund Flow ${ }_{T-1}$} & $-0.18^{*}$ & $-0.17^{* *}$ & $-0.19^{* *}$ & $-0.17^{* * *}$ & $-0.12^{* *}$ & $-0.13^{* * *}$ & $-0.08^{*}$ & & $-0.10^{* *}$ & $-0.11^{*}$ & $-0.12^{* *}$ & \\
\hline & $(-1.87)$ & $(-2.39)$ & $(-2.60)$ & $(-3.28)$ & $(-2.14)$ & $(-2.51)$ & $(-1.70)$ & & $(-2.04)$ & $(-1.73)$ & $(-2.06)$ & \\
\hline \multirow{2}{*}{$\log _{\text {Fund Age }}{ }_{T-1}$} & $-0.13^{* *}$ & $-0.15^{* * *}$ & $-0.13^{* *}$ & -0.13 & $-0.23^{* * *}$ & $-0.17^{* *}$ & $-0.17^{* * *}$ & & $-0.17^{* * *}$ & $-0.17^{*}$ & $-0.18^{* *}$ & \\
\hline & $(-2.30)$ & $(-3.30)$ & $(-2.10)$ & $(-1.53)$ & $(-3.55)$ & $(-2.43)$ & $(-4.09)$ & & $(-2.66)$ & $(-1.90)$ & $(-2.19)$ & \\
\hline \multirow[t]{2}{*}{ Fund Flow Std $_{T-1}$} & $0.32^{* * * *}$ & $0.28^{* * * *}$ & $0.25^{* * * *}$ & $0.30^{* * * *}$ & $0.18^{* * * *}$ & $0.19^{* *^{* *}}$ & $0.24^{* * * *}$ & & $0.26^{* * *}$ & $0.25^{* * *}$ & $0.22^{* *}$ & \\
\hline & $(3.40)$ & $(3.83)$ & $(2.76)$ & $(3.83)$ & $(4.07)$ & $(2.89)$ & $(2.73)$ & & (3.63) & $(3.83)$ & $(2.38)$ & \\
\hline \multirow[t]{2}{*}{ Market Return $_{T-1}$} & $0.13^{*}$ & $0.16^{* *}$ & $0.13^{* *}$ & 0.10 & $0.15^{* *}$ & $0.14^{*}$ & $0.13^{* * * *}$ & & $0.13^{*}$ & $0.12^{*}$ & $0.12^{* * *}$ & \\
\hline & $(1.88)$ & $(2.43)$ & $(2.18)$ & $(1.65)$ & $(2.37)$ & $(1.98)$ & $(2.82)$ & & $(1.86)$ & $(1.69)$ & (2.70) & \\
\hline \multirow[t]{2}{*}{ Expense Ratio $_{T-1}$} & $0.15^{* *}$ & $0.16^{* * *}$ & $0.21^{* * * *}$ & $0.14^{* * *}$ & $0.09^{* *}$ & $0.07^{*}$ & $0.08^{* * * *}$ & & $0.09^{* * * *}$ & $0.12^{*}$ & $0.11^{*}$ & \\
\hline & $(2.59)$ & $(2.54)$ & $(4.53)$ & $(2.55)$ & $(2.57)$ & $(1.78)$ & $(2.67)$ & & $(3.00)$ & $(1.89)$ & $(1.93)$ & \\
\hline \multirow[t]{2}{*}{ Front End Load ${ }_{T-1}$} & $0.19^{* *}$ & $0.21^{* * * *}$ & $0.35^{* * * *}$ & 0.14 & $0.31^{* * * *}$ & $0.25^{* * *}$ & $0.23^{* * * *}$ & & $0.33^{* * *}$ & $0.30^{* * *}$ & $0.24^{* * *}$ & \\
\hline & $(2.07)$ & $(3.07)$ & $(3.22)$ & $(1.57)$ & $(4.81)$ & $(3.75)$ & $(4.87)$ & & $(3.42)$ & $(3.85)$ & $(3.90)$ & \\
\hline \multirow[t]{2}{*}{ Back End Load $_{T-1}$} & 0.04 & $0.04^{*}$ & 0.06 & 0.03 & 0.04 & 0.03 & 0.04 & & $0.04^{*}$ & $0.03^{*}$ & 0.03 & \\
\hline & $(1.15)$ & $(1.68)$ & $(1.30)$ & $(1.05)$ & $(1.63)$ & $(1.40)$ & $(1.29)$ & & $(1.87)$ & $(1.87)$ & $(1.52)$ & \\
\hline \multirow{2}{*}{ Turnover $_{T-1}$} & $0.07^{*}$ & $0.11^{*}$ & $0.09^{*}$ & 0.05 & 0.02 & 0.02 & 0.02 & & 0.02 & 0.02 & 0.02 & \\
\hline & $(1.78)$ & $(1.93)$ & (1.99) & $(1.46)$ & $(0.57)$ & $(0.76)$ & $(0.80)$ & & $(0.89)$ & $(0.56)$ & $(0.65)$ & \\
\hline \multirow[t]{2}{*}{ Morningstar Rating $_{T-1}$} & $0.13^{* *}$ & $0.16^{* * *}$ & $0.11^{* *}$ & $0.16^{* * *}$ & $0.10^{* * *}$ & $0.09^{*}$ & $0.09^{* *}$ & & $0.08^{*}$ & 0.07 & $0.08^{*}$ & \\
\hline & $(2.05)$ & $(3.06)$ & $(2.01)$ & $(3.45)$ & $(2.12)$ & $(1.79)$ & $(2.10)$ & & $(1.66)$ & $(1.46)$ & $(1.84)$ & \\
\hline \multirow[t]{2}{*}{$\Delta$ Morningstar Rating $_{T-1}$} & $0.21^{* * * *}$ & $0.17^{* * *}$ & $0.14^{* *}$ & $0.18^{* * *}$ & $0.24^{* * *}$ & $0.17^{* * * *}$ & 0.07 & & $0.24^{* * *}$ & $0.15^{* * *}$ & 0.05 & \\
\hline & $(3.36)$ & $(3.12)$ & $(2.32)$ & $(3.43)$ & $(2.44)$ & $(3.08)$ & $(1.28)$ & & $(2.87)$ & $(2.57)$ & $(1.16)$ & \\
\hline Adjusted $\mathrm{R}^{2}$ & 0.22 & 0.32 & 0.36 & 0.28 & 0.32 & 0.31 & 0.28 & & 0.35 & 0.31 & 0.28 & \\
\hline $\mathrm{N}$ & 21,219 & 21,219 & 21,219 & 21,219 & 16,032 & 16,033 & 16,033 & & 15,298 & 15,297 & 15,297 & \\
\hline
\end{tabular}

Interpretation: These tables relate annual advertising spending to the one, three, and five year HPR. Mutual fund advertising that features either HPR information (Panel A) or analyst ratings (Panel B) is positively related to past performance (models 1-4). However, the effect is most significant for cases when the fourth (or sixth) year HPR that drops off from the annual 3 and 5 return calculations is the worst. 


\section{Table IV \\ Cross-sectional Determinants of Stale Performance Chasing}

The dependent variable is the annual frequency time series of coefficients $\left(\beta_{n}\right)$ from the regressions: $\Delta m_{t}=\alpha+\beta_{1}$ Return $_{t-1}+$ $\beta_{n}$ Return $_{t-n}+\varepsilon_{t}$, for $n=13,37$, and 61 , where $m_{t}$ is market share defined as mutual fund total net assets (TNA) divided by the total TNA of all funds in the sample in month $t$. Independent variables are the logarithm of: fund TNA, fund age measured from the date of fund inception to the start of the year of $\beta_{n}$ estimation, \# of funds offered by the investment company (family) of the fund and total family TNA. Fund Return and Fund Return Standard Deviation (Std) are calculated over the prior year based on the fund's monthly returns. Morningstar rating is the number of stars ( 1 to 5$)$ assigned to the fund in Morningstar's fund rating system. Advertising is considered fund specific if it mentions at least one fund by name and is otherwise classified as family advertising. Fund specific advertising is subsequently partitioned by whether the fund mentions the fund of interest, if holding period return data is provided or ranking by HPR are mentioned, if the ad features an analyst rating in the absence of HPR info, or the ad provides other non-HPR or analyst type info. 12b-1 is the $12 \mathrm{~b}-1$ fee charged by the fund. The regressions include time fixed effects. Standardized coefficient values are reported with t-statistics in parentheses. T-statistics are calculated with White (1980) heteroskedastic consistent standard errors clustered by fund. Significance at the $10 \%, 5 \%$ and $1 \%$ levels is indicated by ${ }^{*},{ }^{* *},{ }^{* * *}$, respectively.

\begin{tabular}{|c|c|c|c|}
\hline Dependent Variable & $\beta_{13, T}$ & $\beta_{37, T}$ & $\beta_{6 l, T}$ \\
\hline Model & (1) & (2) & (3) \\
\hline \multirow[t]{2}{*}{ Log Fund $\mathrm{TNA}_{T-I}$} & $0.41^{* * * *}$ & $0.19^{* * *}$ & $0.50^{* * *}$ \\
\hline & $(4.89)$ & $(3.07)$ & $(5.75)$ \\
\hline \multirow[t]{2}{*}{$\log$ Fund Age $e_{T-1}$} & 0.01 & $0.48^{* * *}$ & $0.14^{* * * *}$ \\
\hline & $(1.29)$ & $(3.56)$ & $(3.06)$ \\
\hline \multirow[t]{2}{*}{ Log \# Funds in Family F $_{T-1}$} & 0.07 & 0.01 & 0.02 \\
\hline & $(1.26)$ & $(1.44)$ & $(1.30)$ \\
\hline \multirow{2}{*}{$\log _{\text {Family }} \mathrm{TNA}_{T-1}$} & $0.17^{* * *}$ & $0.53^{* * *}$ & $0.24^{* * *}$ \\
\hline & $(3.05)$ & $(6.18)$ & $(2.84)$ \\
\hline \multirow[t]{2}{*}{ Fund Return Std. ${ }_{T-I}$} & $-0.13^{* * *}$ & $-0.14^{*}$ & $-0.20^{* * *}$ \\
\hline & $(-2.70)$ & $(-1.84)$ & $(-3.95)$ \\
\hline \multirow[t]{2}{*}{$12 \mathrm{~b}-1_{T-1}$} & $-0.09^{* *}$ & $-0.26^{* * *}$ & $-0.35^{* * *}$ \\
\hline & $(-2.05)$ & $(-3.70)$ & $(-3.44)$ \\
\hline \multirow[t]{2}{*}{ Morningstar Rating $_{T-1}$} & $-0.09^{*}$ & $-0.23^{* * *}$ & $-0.19^{* * *}$ \\
\hline & $(-1.84)$ & $(-3.23)$ & $(-2.83)$ \\
\hline \multirow[t]{2}{*}{$\Delta$ Morningstar Rating $_{T-1}$} & -0.08 & $-0.12^{* *}$ & $-0.16^{* * * *}$ \\
\hline & $(-1.37)$ & $(-2.23)$ & $(-2.78)$ \\
\hline \multirow{2}{*}{ Family Non-Mutual Fund Ad Spending ${ }_{T-1}$} & -0.03 & -0.04 & -0.04 \\
\hline & $(-1.23)$ & $(-1.14)$ & $(-1.50)$ \\
\hline \multirow[t]{2}{*}{ Family Mutual Fund Ad Spending ${ }_{T-I}$} & $-0.13^{* *}$ & $-0.16^{* *}$ & $-0.15^{* *}$ \\
\hline & $(-2.47)$ & $(-2.54)$ & $(-2.41)$ \\
\hline \multirow[t]{2}{*}{ Fund Specific Ad Spending, Other Fund T $_{T-l}$} & -0.03 & -0.03 & -0.02 \\
\hline & $(-1.04)$ & $(-0.50)$ & $(-0.81)$ \\
\hline \multirow[t]{2}{*}{ Fund Specific Ad Spending, $\mathrm{HPR}_{T-1}$} & $-0.16^{* * * *}$ & $-0.23^{* * *}$ & $-0.21^{\text {***** }}$ \\
\hline & $(-2.73)$ & $(-3.49)$ & $(-3.10)$ \\
\hline \multirow[t]{2}{*}{ Fund Specific Ad Spending, No HPR, Rating ${ }_{T-1}$} & $-0.08^{*}$ & $-0.10^{*}$ & $-0.13^{* *}$ \\
\hline & $(-1.82)$ & $(-1.88)$ & $(-2.56)$ \\
\hline \multirow[t]{2}{*}{ Fund Specific Ad Spending, No HPR, No Rating } & -0.02 & -0.04 & -0.02 \\
\hline & $(-0.41)$ & $(-0.35)$ & $(-0.27)$ \\
\hline \multirow[t]{2}{*}{ Institutional Fund Indicator $_{T-I}$} & -0.08 & $-0.09^{* *}$ & -0.06 \\
\hline & $(-1.47)$ & $(-2.01)$ & $(-1.52)$ \\
\hline Adjusted $\mathrm{R}^{2}$ & 0.37 & 0.38 & 0.40 \\
\hline $\mathrm{N}$ & 37,198 & 35,232 & 32,709 \\
\hline
\end{tabular}

Interpretation: This table explores the determinants of stale return chasing by investors. Stale return chasing is higher for funds with higher Morningstar ratings, increasing Morningstar ratings, and for funds that advertise HPR related information in magazine ads. 


\section{Table V \\ Time Series Determinants of Stale Performance Chasing}

In this table, the dependent variable is the annual frequency time series of coefficients $\left(\beta_{n}\right)$ from the regressions: $\Delta m_{t}=$ $\alpha+\beta_{1}$ Return $_{t-1}+\beta_{n}$ Return $_{t-n}+\varepsilon_{t,}$ for $n=13,37$ and 61, where $m_{t}$ is market share defined as mutual fund total net assets (TNA) divided by the total TNA of all funds in the sample in month $t$. Mutual Fund Ad Spending is the total expenditure on advertising in magazines that mention the fund of interest, partitioned by whether the ad reports horizon based information, analyst rating or neither. As proxies for market conditions we use: 1) the Chicago Board Option Exchange Volatility Index (VIX) and 2) the CFNAI index produced by the Chicago Federal Reserve. The regressions include time fixed effects. Standardized coefficient values are reported with t-statistics in parenthesis. T-statistics are calculated with White (1980) heteroskedastic consistent standard errors clustered by fund. Control variables from Table IV (fund visibility proxies and Morningstar Rating and $\Delta$ Morningstar Rating) are included in the models, but are suppressed in the interest of brevity. Significance at the $10 \%, 5 \%$ and $1 \%$ levels is indicated by ${ }^{*},{ }^{* *},{ }^{* * *}$, respectively.

\begin{tabular}{|c|c|c|c|}
\hline Dependent Variable & $\beta_{13, T}$ & $\beta_{37, T}$ & $\beta_{61, T}$ \\
\hline Model & (1) & (2) & (3) \\
\hline \multirow[t]{2}{*}{$\mathrm{VIX}_{T-1}$} & $-0.40^{* * *}$ & $-0.11^{* *}$ & $-0.37^{* * *}$ \\
\hline & $(-4.49)$ & $(-2.03)$ & $(-4.78)$ \\
\hline \multirow[t]{2}{*}{ CFNAI $_{T-1}$} & $0.12^{*}$ & $0.54^{* * *}$ & $0.38^{* * *}$ \\
\hline & $(1.70)$ & $(6.83)$ & $(6.93)$ \\
\hline \multirow[t]{2}{*}{ General Ad Spending $_{T-1}$} & $-0.04^{*}$ & -0.03 & -0.03 \\
\hline & $(-1.76)$ & $(-0.42)$ & $(-0.92)$ \\
\hline \multirow{2}{*}{ Ad Spending HPR Data ${ }_{T-1}$} & $-0.14^{* *}$ & $-0.18^{* * * *}$ & $-0.11^{* *}$ \\
\hline & $(-2.16)$ & $(-3.45)$ & $(-2.22)$ \\
\hline \multirow[t]{2}{*}{ Fund Specific Ad Spending, No HPR, Rating ${ }_{T-1}$} & $-0.16^{* * *}$ & $-0.28^{* * *}$ & $-0.24^{* * *}$ \\
\hline & $(-2.68)$ & $(-3.82)$ & $(-3.73)$ \\
\hline \multirow[t]{2}{*}{ Fund Specific Ad Spending, No HPR, No Rating ${ }_{T-l}$} & -0.04 & -0.07 & -0.03 \\
\hline & $(-1.50)$ & $(-1.62)$ & $(-0.96)$ \\
\hline \multirow{2}{*}{ VIX $\times$ General Ad Spending ${ }_{T-I}$} & -0.05 & -0.03 & -0.05 \\
\hline & $(-1.54)$ & $(-0.65)$ & $(-0.96)$ \\
\hline \multirow[t]{2}{*}{ VIX $\times$ Fund Specific Ad Spending, $\mathrm{HPR}_{T-I}$} & $-0.20^{* * *}$ & $-0.19^{* *}$ & $-0.11^{*}$ \\
\hline & $(-3.72)$ & $(-2.41)$ & $(-1.93)$ \\
\hline \multirow[t]{2}{*}{ VIX $\times$ Fund Specific Ad Spending, No HPR, Rating ${ }_{T-I}$} & $-0.19^{* * *}$ & $-0.13^{* * *}$ & $-0.17^{* * *}$ \\
\hline & $(-3.14)$ & $(-2.82)$ & $(-2.98)$ \\
\hline \multirow{2}{*}{ VIX $\times$ Fund Specific Ad Spending, No HPR, No Rating ${ }_{T-I}$} & $-0.07^{*}$ & $-0.07^{*}$ & $-0.07^{*}$ \\
\hline & $(-1.65)$ & $(-1.77)$ & $(-1.74)$ \\
\hline \multirow[t]{2}{*}{$1 /$ CFNAI $\times$ General Ad Spending ${ }_{T-I}$} & -0.05 & -0.05 & -0.03 \\
\hline & $(-0.66)$ & $(-1.41)$ & $(-1.51)$ \\
\hline \multirow[t]{2}{*}{ 1/CFNAI $\times$ Fund Specific Ad Spending, $\mathrm{HPR}_{T-1}$} & $-0.16^{* * *}$ & $-0.07^{*}$ & $-0.09^{* *}$ \\
\hline & $(-2.54)$ & $(-1.95)$ & $(-2.05)$ \\
\hline \multirow[t]{2}{*}{ 1/CFNAI $\times$ Fund Specific Ad Spending, No HPR, Rating ${ }_{T-1}$} & $-0.12^{* *}$ & $-0.07^{* *}$ & $-0.09^{*}$ \\
\hline & $(-2.10)$ & $(-2.10)$ & $(-1.88)$ \\
\hline \multirow[t]{2}{*}{ 1/CFNAI $\times$ Fund Specific Ad Spending, No HPR, No Rating ${ }_{T-I}$} & -0.05 & -0.06 & -0.07 \\
\hline & $(-1.38)$ & $(-1.04)$ & $(-1.35)$ \\
\hline Adjusted $\mathrm{R}^{2}$ & 0.35 & 0.36 & 0.36 \\
\hline $\mathrm{N}$ & 37,198 & 35,232 & 32,709 \\
\hline Controls & Yes & Yes & Yes \\
\hline
\end{tabular}


Interpretation: This table extends the examination of the determinants of stale return chasing in Table IV. Stale return chasing is higher when there is greater uncertainty in financial markets. Funds that advertise in these periods of uncertainty, realize incrementally greater stale return chasing. 


\section{Table VI}

\section{Stale Performance Chasing and Mutual Fund Fees}

In this table, we relate mutual fund expense ratios $(\mathrm{Fee})$ and fee waivers to the annual frequency time series of holding period returns and coefficients $\left(\beta_{n}\right)$ from the regressions: $\Delta m_{t}=\alpha+\beta_{1}$ Return $_{t-1}+\beta_{n}$ Return $_{t-n}+\varepsilon_{t,}$ for $n=13$, 37, 61, where $m_{t}$ is market share defined as mutual fund total net assets (TNA) divided by the total TNA of all funds in the sample in month $t$. Expense ratio is the percentage of total net assets paid by investors for the fund's operating expenses. Fee is total expenses paid by investors, expressed as a percentage of total net assets (\%Fee). Fee waiver is the reduction in fees as a percentage of net assets applied to the expense ratio reported in the fund prospectus. The key independent variables are holding period returns (HPR) calculated using monthly returns over the prior 1, 3, and 5 year horizons (for example, $H P R_{T-1}^{3 \text { Year }}$ refers to the 3 year HPR ending in year $\left.T-1\right)$ The models are partitioned by the annual return that drops from the 3 and 5 year HPR horizon (i.e. the 1 year HPR 4 years prior $H P R_{T-4}^{1}$ Year and the 1 year HPR 6 years prior $H P R_{T-6}^{1}$ Year ). Objective and Excess fund $\beta_{n}$ values are reported where Objective $\beta_{n}$ is calculated by relating fund $\Delta m_{t}$ to value-weighted mean objective returns and Excess $\beta_{n}$ is calculated by relating fund $\Delta m_{t}$ to fund returns in excess of the value-weighted mean objective return. Control variables are as previously defined, except fund and family alpha which are calculated using the Fama-French 4-factor model. The models include time fixed effects. Standardized coefficient values are reported with tstatistics in parenthesis. T-statistics are calculated with White (1980) heteroskedastic consistent standard errors clustered by fund. In Panel B, control variable coefficients values are suppressed in the interest of brevity. Significance at the $10 \%, 5 \%$ and $1 \%$ levels is indicated by ${ }^{*},{ }^{* *},{ }^{* * *}$, respectively.

Panel A: Fees and Stale Performance Chasing

\begin{tabular}{|c|c|c|c|c|c|c|}
\hline \multirow[t]{2}{*}{ Dependent Variable } & \multicolumn{3}{|c|}{$\% \mathrm{Fee}_{T}$} & \multicolumn{3}{|c|}{$\Delta \%$ Waiver $_{T}$} \\
\hline & $n=13$ & $n=37$ & $n=61$ & $n=13$ & $n=37$ & $n=61$ \\
\hline Model & (1) & (2) & (3) & (7) & (8) & (9) \\
\hline \multirow{2}{*}{ Objective $\beta_{n, T-1}$} & $-0.20^{* *}$ & $-0.24^{* * *}$ & $-0.25^{* * *}$ & $0.17^{* *}$ & $0.21^{* * *}$ & $0.16^{* * *}$ \\
\hline & $(-2.25)$ & $(-4.25)$ & $(-3.78)$ & $(2.12)$ & $(3.30)$ & $(3.21)$ \\
\hline \multirow[t]{2}{*}{ Excess $\beta_{n, T-1}$} & $-0.16^{* *}$ & $-0.28^{* * * *}$ & $-0.23^{* * *}$ & $0.21^{* * *}$ & $0.16^{* *}$ & $0.29^{* *}$ \\
\hline & $(-2.27)$ & $(-4.52)$ & $(-3.64)$ & $(3.24)$ & $(2.08)$ & $(2.28)$ \\
\hline \multirow[t]{2}{*}{ Fund $\mathrm{Fee}_{T-1}$} & $0.12^{*}$ & $0.12^{* *}$ & 0.07 & $-0.15^{* * * *}$ & $-0.17^{* * * *}$ & -0.07 \\
\hline & $(1.95)$ & (2.38) & (1.16) & $(-2.95)$ & $(-3.80)$ & $(-1.37)$ \\
\hline \multirow[t]{2}{*}{ Fund Alpha ${ }_{T-1}$} & $0.24^{* * *}$ & $0.13^{* *}$ & $0.25^{* * *}$ & $-0.23^{* * *}$ & $-0.17^{* * *}$ & $-0.18^{* *}$ \\
\hline & $(3.46)$ & $(2.39)$ & $(2.67)$ & $(-4.00)$ & $(-3.36)$ & $(-2.32)$ \\
\hline \multirow{2}{*}{$\Delta$ Market Share ${ }_{T-1}$} & $0.16^{* * *}$ & $0.18^{* * *}$ & $0.10^{* *}$ & $-0.11^{* *}$ & $-0.12^{* *}$ & $-0.09^{*}$ \\
\hline & $(2.91)$ & $(3.09)$ & $(2.08)$ & $(-2.33)$ & $(-2.56)$ & $(-1.80)$ \\
\hline \multirow[t]{2}{*}{$\Delta$ Market Share $\mathrm{Std}_{\cdot T-I}$} & -0.05 & -0.09 & -0.07 & -0.05 & $-0.08^{*}$ & -0.05 \\
\hline & $(-0.94)$ & $(-1.58)$ & $(-1.51)$ & $(-1.22)$ & $(-1.70)$ & $(-1.63)$ \\
\hline \multirow[t]{2}{*}{ Fund Age $\mathbf{A}_{T-1}$} & 0.01 & 0.01 & 0.02 & 0.01 & 0.01 & 0.02 \\
\hline & $(1.05)$ & $(1.40)$ & $(1.16)$ & $(1.63)$ & $(1.55)$ & $(1.21)$ \\
\hline \multirow{2}{*}{ Log Fund TNA ${ }_{T-1}$} & $-0.09^{* * *}$ & $-0.09^{* *}$ & -0.05 & $0.09^{* *}$ & $0.07^{*}$ & 0.04 \\
\hline & $(-2.62)$ & $(-2.04)$ & $(-1.59)$ & $(2.04)$ & (1.69) & $(0.93)$ \\
\hline \multirow[t]{2}{*}{ Family Alpha $a_{T-1}$} & 0.15 & $0.16^{* *}$ & $0.23^{* * *}$ & $-0.18^{* *}$ & $-0.16^{* * * *}$ & $-0.23^{* * *}$ \\
\hline & $(2.15)$ & $(2.40)$ & (3.99) & $(-2.05)$ & $(-4.32)$ & $(-4.05)$ \\
\hline \multirow[t]{2}{*}{ Log Family TNA $_{T-1}$} & $-0.11^{* * *}$ & $-0.06^{*}$ & -0.11 & $0.11^{*}$ & $0.07^{*}$ & $0.13^{* *}$ \\
\hline & $(-3.01)$ & $(-1.86)$ & $(-1.47)$ & $(1.83)$ & $(1.67)$ & $(2.11)$ \\
\hline \multirow[t]{2}{*}{ Log Objective TNA $_{T-I}$} & -0.05 & -0.02 & -0.01 & -0.05 & $-0.02^{*}$ & -0.01 \\
\hline & $(-1.29)$ & $(-1.11)$ & $(-1.05)$ & $(-1.15)$ & $(-1.97)$ & $(-0.75)$ \\
\hline \multirow[t]{2}{*}{ Morningstar Rating $_{T-1}$} & $0.12^{* *}$ & $0.15^{* * *}$ & $0.18^{* * *}$ & $-0.10^{* *}$ & $-0.13^{*}$ & $-0.23^{* * *}$ \\
\hline & $(2.54)$ & $(2.82)$ & $(3.24)$ & $(-2.13)$ & $(-1.76)$ & $(-3.12)$ \\
\hline \multirow[t]{2}{*}{$\Delta$ Morningstar Rating ${ }_{T-1}$} & $0.09^{*}$ & $0.15^{* *}$ & $0.22^{* *}$ & $-0.14^{* * *}$ & $-0.11^{* *}$ & $-0.20^{* *}$ \\
\hline & $(1.74)$ & $(2.35)$ & $(2.44)$ & $(-3.06)$ & $(-2.47)$ & $(-2.33)$ \\
\hline Adjusted $R^{2}$ & 0.25 & 0.22 & 0.29 & 0.23 & 0.21 & 0.26 \\
\hline $\mathrm{N}$ & 28,032 & 28,032 & 28,032 & 28,032 & 28,032 & 28,032 \\
\hline
\end{tabular}


Panel B: Fees and Holding Period Returns

\begin{tabular}{|c|c|c|c|c|c|c|c|c|c|}
\hline \multirow{3}{*}{$\begin{array}{l}\text { Dependent Variable } \\
\text { Partition Variable } \\
\text { Model/Partition }\end{array}$} & \multicolumn{9}{|c|}{ ב $\Delta \%$ Waiver $_{T}$} \\
\hline & \multirow{2}{*}{$\begin{array}{c}\text { Full Sample } \\
\text { (1) }\end{array}$} & \multicolumn{4}{|c|}{$H P R_{T-4}^{1 \text { Year }}$} & \multicolumn{4}{|c|}{$H P R_{T-6}^{1 \text { Year }}$} \\
\hline & & Low & Mid & High & $L-H$ & Low & Mid & High & $L-H$ \\
\hline \multirow[t]{2}{*}{$H P R_{T-1}^{1 \text { Year }}$} & $-0.20^{* * *}$ & $-0.31^{* * *}$ & $-0.25^{* * *}$ & $-0.21^{* * *}$ & $-0.10^{* *}$ & $-0.27^{* * *}$ & $-0.17^{* * *}$ & $-0.12^{* *}$ & $-0.16^{* * *}$ \\
\hline & $(-2.86)$ & $(-4.09)$ & $(-3.62)$ & $(-3.20)$ & $(-2.43)$ & $(-3.56)$ & $(-2.64)$ & $(-2.18)$ & $(-2.92)$ \\
\hline \multirow[t]{2}{*}{$H P R_{T-1}^{3 \text { Year }}$} & $-0.18^{* *}$ & $-0.29^{* * *}$ & $-0.25^{* * *}$ & $-0.16^{* * *}$ & $-0.14^{* * *}$ & $-0.24^{* * *}$ & $-0.26^{* * *}$ & $-0.16^{* * *}$ & $-0.08^{*}$ \\
\hline & $(-2.58)$ & $(-3.90)$ & $(-3.60)$ & $(-2.99)$ & $(-2.64)$ & $(-3.69)$ & $(-3.52)$ & $(-2.78)$ & $(-1.94)$ \\
\hline \multirow[t]{2}{*}{$H P R_{T-1}^{5 \text { Year }}$} & $-0.19^{* * * *}$ & $-0.30^{* * *}$ & $-0.22^{* * *}$ & $-0.14^{* *}$ & $-0.16^{* * *}$ & $-0.33^{* * *}$ & $-0.18^{* * *}$ & $-0.15^{* *}$ & $-0.18^{* * *}$ \\
\hline & $(-2.70)$ & $(-3.63)$ & $(-3.13)$ & $(-2.19)$ & $(-2.89)$ & $(-4.20)$ & $(-2.64)$ & $(-2.54)$ & $(-2.93)$ \\
\hline Adjusted $\mathrm{R}^{2}$ & 0.24 & 0.27 & 0.24 & 0.26 & & 0.29 & 0.23 & 0.20 & \\
\hline $\mathrm{N}$ & 28,032 & 26,144 & 26,144 & 26,144 & & 21,007 & 21,007 & 21,007 & \\
\hline Controls & Yes & Yes & Yes & Yes & & Yes & Yes & Yes & \\
\hline
\end{tabular}

Interpretation: End return related improvements in HPRs increase investor demand. Mutual fund managers respond to this increase in demand by increasing mutual fund fees via waiver reductions. 


\section{Figure 1}

\section{Sample Advertisements}

This figure depicts sample advertisements that feature HPRs (Panel A) and do not (Panel B).

Panel A: Featuring HPRs

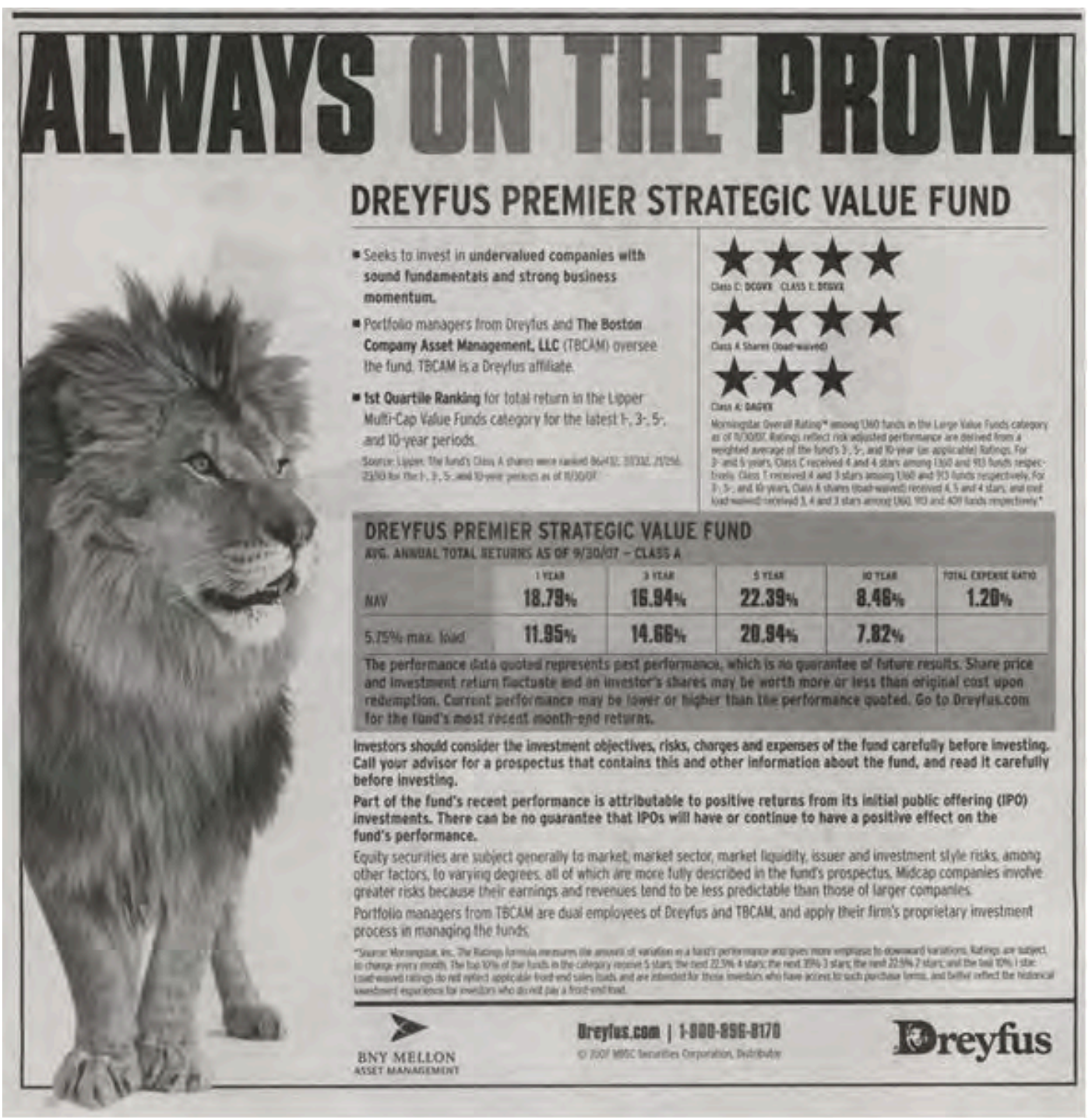


Panel B: Excluding HPRs

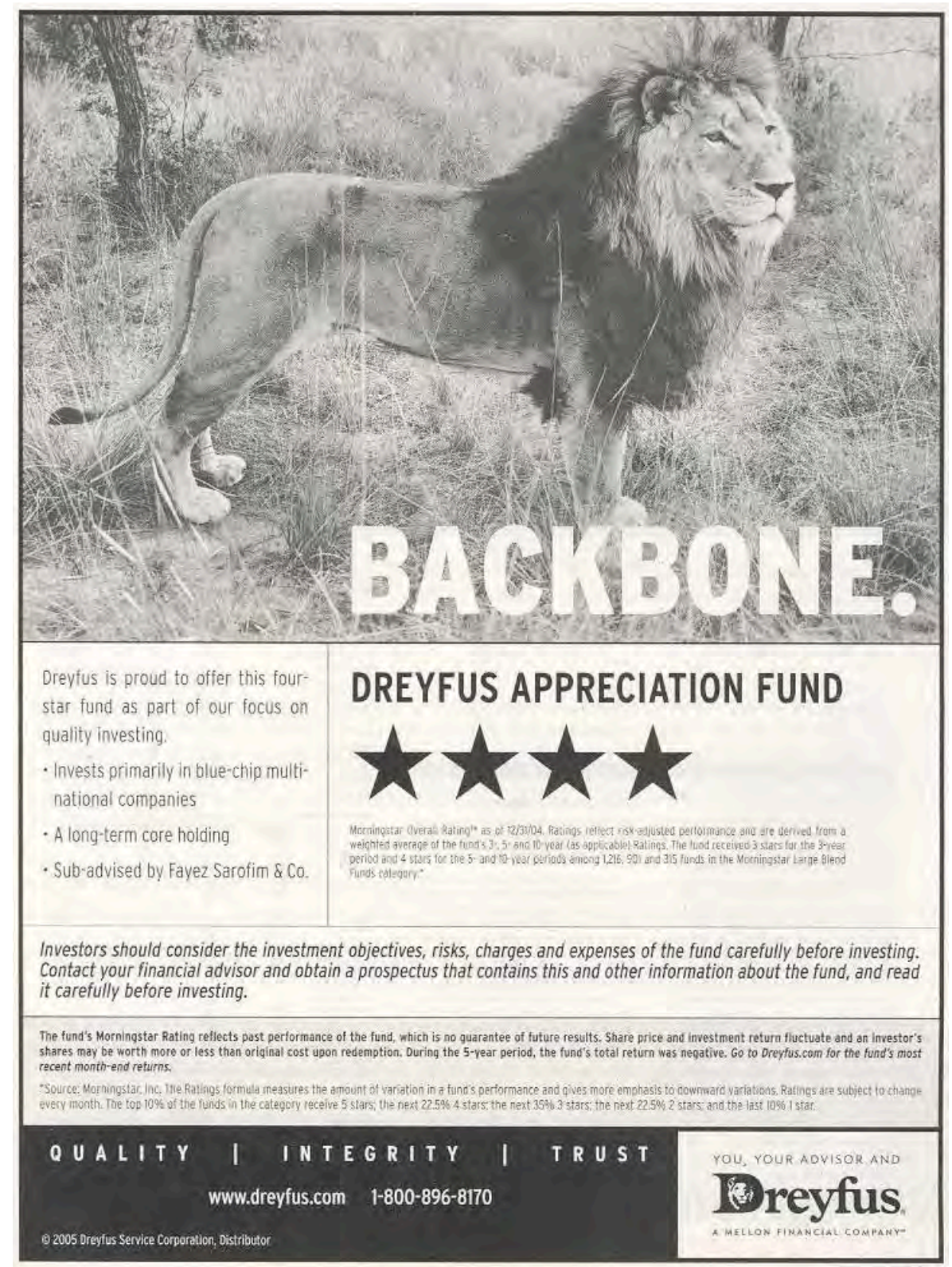

